\title{
Datação por traços de fissão e geocronologia do Plio-Quaternário
}

\author{
Gérard POUPEAU', François-Xavier LE BOURDONNEC², M. Lidia VIGNOL-LELARGE³ \& \\ Olivier DORIGHEL ${ }^{2}$ \\ 1 In memoriam. \\ ${ }^{2}$ Institut de Recherche sur les Archéomatériaux, UMR 5060 CNRS-Université de Bordeaux, Centre de \\ Recherche en Physique Appliquée à l'Archéologie. Maison de l'Archéologie, Esplanade des Antilles, 33607, \\ Pessac, França (francois.lebourdonnec@\&u.u-bordeaux3, obsidiana@aliceads1.fr). \\ ${ }^{3}$ Laboratório de Termocronologia LGI-CPGq, Instituto de Geociências, Univerdidade Federal do Rio Grande \\ do Sul. Av. Bento Gonçalves 9500, CEP 95500-970, Porto Alegre, RS, Brasil (lidia.vignol@ufrgs.br).
}

\begin{abstract}
Resumo. A datação por traços de fissão aplicada em estudos do Plio-Quaternário é pouco conhecida no Brasil. O objetivo principal do presente manuscrito é expor e fazer ampla divulgação das potencialidades desta metodologia aos pesquisadores que atuam nesse domínio temporal das ciências da natureza no nosso país. Para tal são apresentados detalhadamente todos os aspectos da datação por Traços de Fissão. São abordados os princípios básicos da datação por Traços de Fissão, a equação da idade, precisão e acurácia, as técnicas analíticas utilizadas em função das particularidades e natureza dos materiais, suas limitações assim como os casos de sucesso. Também são mostrados diversos estudos de caso com exemplos de utilização da metodologia nas variadas áreas de aplicação de pesquisas do Plio-Quaternário, inclusive em arqueologia.
\end{abstract}

Palavras-chave. Plio-Quaternário, Traços de Fissão, Proveniência, Obsidiana, Tefra.

Abstract. FISSION TRACK DATING AND PLIO-QUATERNARY GEOCHRONOLOGY. The application of fission tracks dating in Plio-Quaternary studies is poorly known in Brazil. The main objective of this manuscript is to present and greatly disclose the potential of this methodology to researchers working in this temporal field of natural sciences in our country. For this, all aspects of the fission tracks dating applied to materials of the Plio-Quaternary are presented in details. The basic principles of fission tracks dating, the equation of age, precision and accuracy, the analytical techniques used in function of the particularities and nature of the materials are addressed, as well as its limitations and cases of success. Also, there are several study cases with examples of the use of the methodology in various areas of application in Plio-Quaternary research, including archeology.

Keywords. Plio-Quaternary, Fission Tracks, Provenance, Obsidian, Tephra.

\section{Introdução}

O método de datação por Traços de Fissão (TF) é hoje amplamente utilizado nas investigações de eventos de baixa temperatura nas mais diversas áreas. Em geologia, o método tem sido aplicado em estudos de eventos tectônicos, como exumação ou soterramento de blocos, reativação de falhas, mineralizações, intrusões magmáticas, histórias térmicas de bacias sedimentares, além de estudos em geomorfologia quantitativa (Wagner \& Van Den
Haute, 1992; Braun et al., 2006). Este método termocronológico permite quantificar a duração e as taxas de resfriamento e/ou aquecimento dos eventos da superfície e sub-superfície terrestre. Tipicamente, os materiais utilizados são os minerais apatita, zircão, esfeno, epidoto e os vidros, tefras e obsidianas. Em geocronologia, na maioria dos casos, o intervalo de tempo considerado é da ordem de vários milhões até centenas de milhões de anos. Entretanto, esse não é o único domínio temporal do método TF. Com efeito, ele também é aplicado em estudos 
mais recentes, do Plio-Quaternário, onde o lapso de tempo a ser considerado é dos últimos 6 milhões de anos, o que torna a metodologia particularmente interessante, principalmente por utilizar materiais de sílica. Nos materiais de sílica, como as obsidianas, a datação só é possível porque os teores de urânio são elevados. O método de datação por TF quando aplicado aos materiais do Plio-Quaternário permite investigar a evolução e impacto dos seres humanos sobre o ambiente, além de estudar os processos geológicos e estabelecer uma correlação e sequência temporal entre os eventos. Tendo como motivação principal a divulgação das potencialidades e limitações da datação por Traços de Fissão aplicada ao período recente da história da Terra e da humanidade, foi elaborado este manuscrito, no qual é apresentado o estado da arte em geocronologia do Plio-Quaternário. São apresentados os princípios da datação por Traços de Fissão, a derivação da equação da idade, precisão e acurácia das idades TF, datação dos diversos materiais, obsidianas e tefras, minerais, artefatos e suas aplicações em pesquisas do Plio-Quaternário e arqueologia, constituindo-se desta forma em um verdadeiro manual de termocronologia para aqueles que desejam aprofundar-se nas datações TF do PlioQuaternário.

\section{Fissão nuclear e geocronologia}

A fissão espontânea é um dos processos de desintegração nuclear que afeta os isótopos pesados de número atômico $Z \geq 90$ e de número de massa $A \geq 230$. Assim, os isótopos que fissionam espontaneamente pertencem à série dos actínideos, os quais na maioria decaem igualmente através de outros processos, entre os quais a radioatividade $\alpha$.

Os únicos que devem ser considerados sobre a Terra, por razões de abundância, são os isótopos naturais ${ }^{232} \mathrm{Th},{ }^{235} \mathrm{U}$ e ${ }^{238} \mathrm{U}$. Todavia, para esses, a fissão tem uma probabilidade de ocorrência muito menor do que a radioatividade $\alpha$ (tabela 1). No caso mais favorável, caso do ${ }^{238} \mathrm{U}$, há somente uma fissão a cada dois milhões de desintegrações $\alpha$. Considerando as taxas relativas de fissão espontânea do tório e do urânio (tabela 1, coluna da direita), deve-se considerar apenas o isótopo ${ }^{238} \mathrm{U}$ em geocronologia pelos traços de fissão (TF).

A fissão espontânea do ${ }^{238} \mathrm{U}$ deu origem a dois métodos de datação. No método U-Xe (Khlopin \& Gerlin, 1947) e seus desdobramentos (Shukolyukov et al., 1974; Meshick et al., 1987), o importante é a quantidade dos isótopos fissiogênicos do xenônio. Tendo permanecido em um estágio anedótico, eles se aplicam somente para os minerais ricos em urânio cujas idades são mais antigas do que o Plioceno (>5,3 Ma). Na datação por traços de fissão, considerase o dano de irradiação causado, no mineral ou no vidro, pelo relaxamento da energia de fissão. A acumulação desses danos, ou 'traços de fissão', a partir de um tempo $t_{0}$ a ser definido até o tempo presente, permite obter a idade de um 'evento' conquanto que se conheça o teor em urânio na fase a ser datada. Utiliza-se para isso uma outra propriedade desse elemento, a fissão induzida de ${ }^{235} \mathrm{U}$ por captura neutrônica. Com efeito, a partir da fissão induzida do ${ }^{235} \mathrm{U}$ por captura de nêutrons térmicos e da relação natural ${ }^{235} \mathrm{U} /{ }^{238} \mathrm{U}$, é possível determinar o conteúdo de ${ }^{238} \mathrm{U}$ das amostras a serem datadas. A datação por traços de fissão foi introduzida, de um ponto de vista teórico, por Price \& Walker em 1963 e logo no ano seguinte, os resultados dos primeiros programas-teste foram publicados (Fleischer et al., 1964; Maurette et al., 1964). A datação por traços de fissão foi progressivamente reconhecida como um dos grandes métodos da geocronologia isotópica. Ela é notoriamente indispensável em geomorfologia quantitativa, ou na reconstituição da história térmica e tectônica de bacias sedimentares (Wagner \& Van den Haute, 1992). Na datação das rochas vulcânicas, ela é particularmente adaptada no tratamento dos termos mais ácidos, ou seja, das rochas mais ricas em sílica. É precisamente esse último aspecto que constitui o seu principal interesse nas aplicações em geologia do Plioquaternário até a Pré-História.

\section{Da fissão aos traços de fissão}

Durante a fissão, o núcleo de um átomo de urânio gera dois núcleos-filhos, ou fragmentos de fissão, de massas quase idênticas (Fig. 1), 
e estatisticamente com 2,07 nêutrons livres. Os produtos leves de fissão são isótopos notadamente de $\mathrm{Br}, \mathrm{Kr}$, Sr, Zr, e para os fragmentos pesados, de I, Xe, Cs, Ba, La. A energia liberada no momento de uma fissão, da ordem de $200 \mathrm{MeV}$, é muito superior àquela de uma desintegração a, sempre inferior a $10 \mathrm{MeV}$. Mais de $80 \%$ dela incumbe aos fragmentos de fissão sob a forma de energia cinética (Fig. 2), o resto repartindose entre partículas ejetadas, nêutrons, elétrons, neutrinos e as radiações gama de relaxamento. A conservação da quantidade de movimento faz com que os fragmentos de fissão sejam ejetados linearmente segundo direções opostas. Nos minerais e vidros naturais, que são bons isolantes, o percurso de um fragmento de fissão se situa em torno de 7-8 $\mu$ m para o zircão (Krishnaswami et al., 1974), 9-10 um para a apatita (Bhandari et al., 1971) e 12 um nas micas. A energia de uma fissão, muito superior aos poucos eV das energias de ligação entre os átomos das redes cristalinas tridimensionais ou daquelas que constituem as cadeias silicatadas dos vidros naturais, é assim dissipada localmente. Sendo os átomos-filhos da fissão fortemente ionisados, admite-se, como no modelo de pontas de explosão iônica de Fleischer et al. (1965a), que eles provocam importantes danos de irradiação, conduzindo, ao longo de sua trajetória, a uma zona linear muito deprimida em átomos, rodeada de um halo, ele mesmo muito perturbado (Fig. 3). Um modelo alternativo para explicar o mecanismo de formação de traços de fissão é o modelo de pico térmico (thermal Spike model) proposto por Seitz \& Koehler em 1956 (apud Toulemonde et al., 1993). Neste modelo é postulado que a transferência de energia se dá por processo térmico. Diversos autores (Toulemonde et al., 1993; Szeines, 1996; Chadderton, 2003) revisitaram este modelo e o consideram adequado para descrever a formação de traços latentes em materiais como obsidianas e minerais. A observação desses 'traços' em microscopia eletrônica de transmissão mostra que o diâmetro desse halo não ultrapassa uma centena de Ångströms. Assim, não sendo visíveis em microscopia óptica, essas estruturas nomeiam-se 'traços latentes'. É a perenidade destas 'cicatrizes' nos minerais e vidros naturais que é utilizada na datação por traços de fissão.

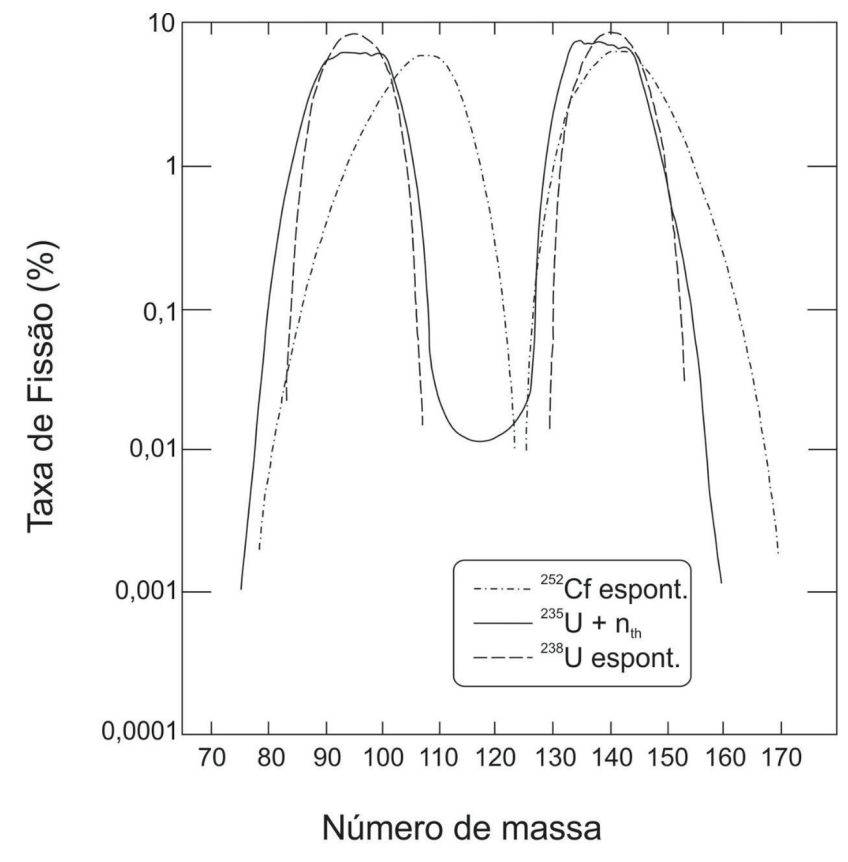

Figura 1. Distribuição em massa dos fragmentos de fissão induzida de ${ }^{235} \mathrm{U}$ por captura neutrônica e de fissão espontânea de ${ }^{238} \mathrm{U}$ (segundo Von Gunten, 1969).

Figure 1. Mass distribution of ${ }^{235} \mathrm{U}$ induced fission fragments by neutronic capture and spontaneous fission of ${ }^{238} \mathrm{U}$ (according to Von Gunten, 1969).

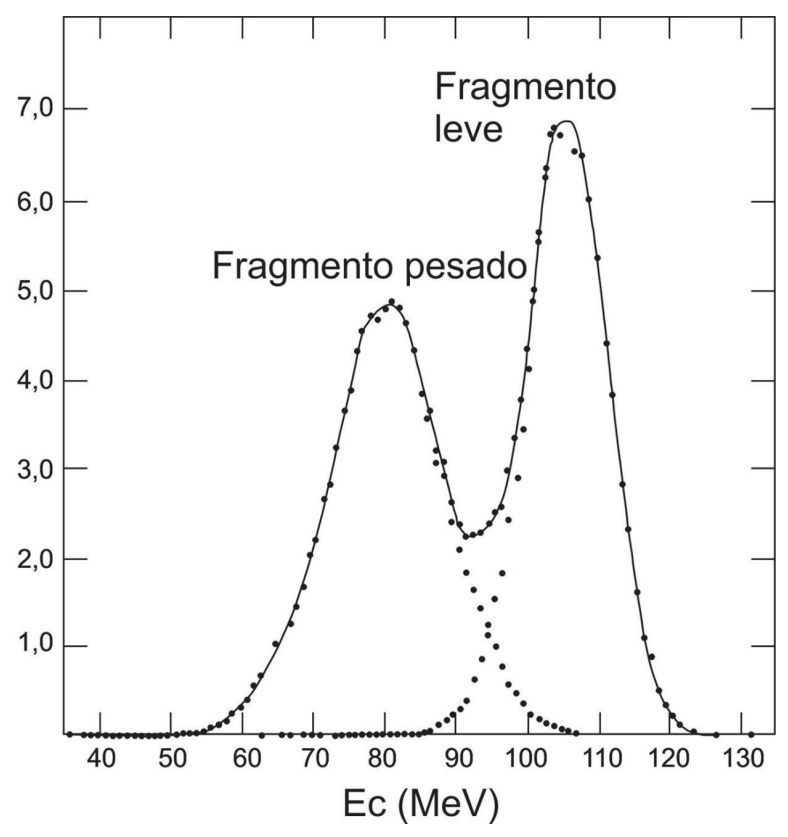

Figura 2. Distribuição da energia cinética devida aos fragmentos de fissão espontânea de ${ }^{252} \mathrm{Cf}$. São os fragmentos mais leves que possuem as energias mais altas (segundo Whetstone, 1963).

Figure 2. Distribution of kinetic energy due to spontaneous fission fragments of ${ }^{252} \mathrm{Cf}$. The lightest fragments have the highest energies (according to Whetstone, 1963). 


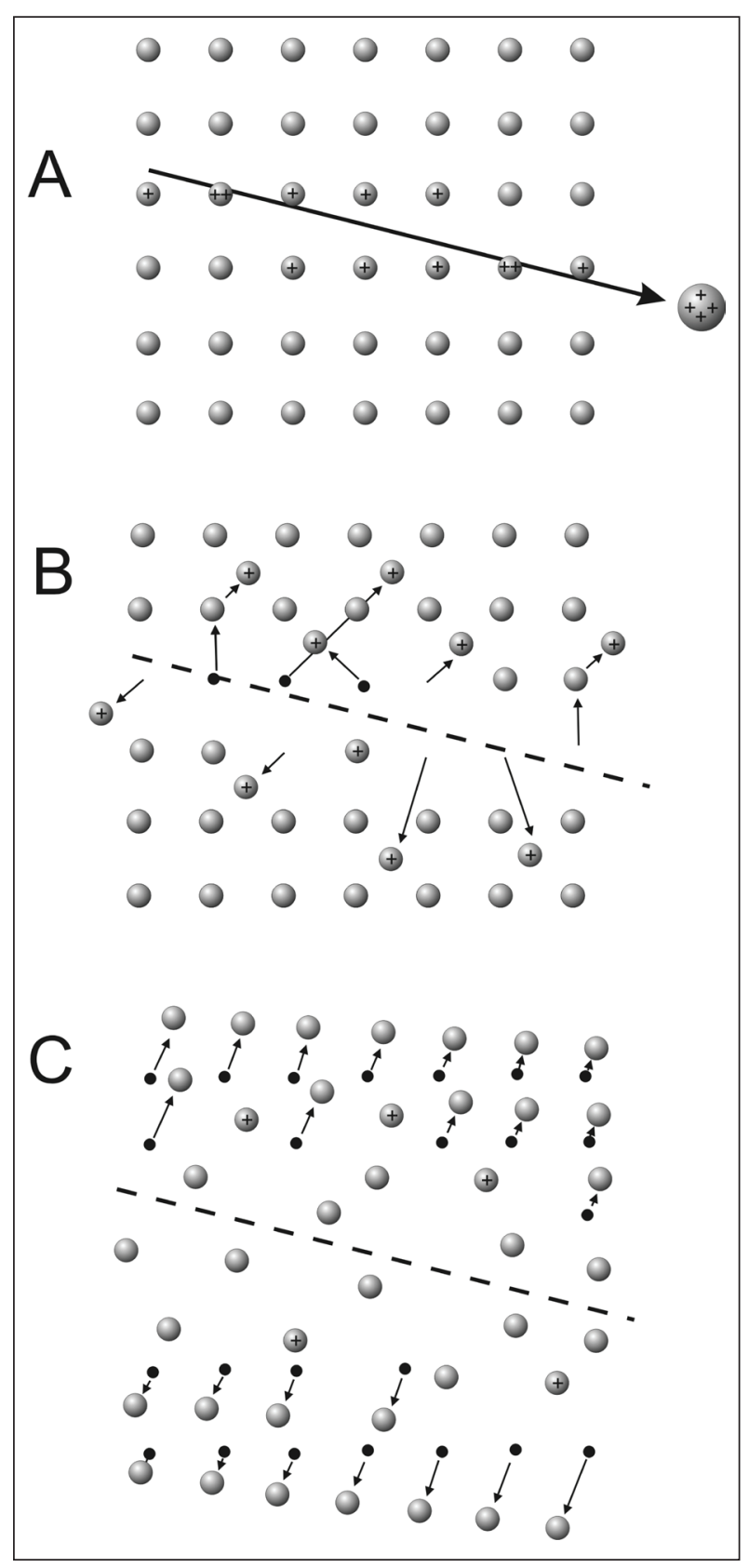

Figura 3. Mecanismo de formação dos traços latentes nos minerais, segundo o modelo de pontas de explosão iônica de Fleischer et al. (1965a). A) Ionização ao longo da trajetória de um fragmento de fissão; B) Repulsões coulombianas resultantes; C) Relaxamento da região perturbada deixando ao longo dessa trajetória uma zona central deprimida em átomos, circundada por uma região de rede sob tensão elástica enriquecida em interstícios (segundo Fleischer et al., 1975).

Figure 3. Mechanism of formation of latent tracks in minerals, according to the 'ion explosion spike' model of Fleischer et al. (1965a) A) lonizations along the trajetory of a fission fragment; $B$ ) Resulting Coulombian repulsions; C) Relaxation of the disturbed region leaving along this trajectory a central zone lacking in atoms, surrounded by a network region under elastic tension enriched in interstices (segundo Fleischer et al., 1975).
Os traços latentes possuem um forte potencial químico e são consequentemente suscetíveis de reagir mais fortemente face às soluções agressivas. Assim é possível, graças a um agente químico apropriado, alargar esses traços por dissolução preferencial até os tornar visíveis em microscopia óptica ao longo da maior parte de seus comprimentos. Em geocronologia, são os traços assim 'revelados', intersectando uma superfície de polimento do material a ser datado, que são utilizados. Geralmente, efetuase um ataque com auxílio de ácidos (Wagner \& Van den Haute, 1992, p. 240-242). No processo de revelação dos traços de fissão, com o uso de reagentes químicos, todos os materiais sofrem um ataque superficial conhecido como bulk etching. Nos minerais, a dissolução inicia-se praticamente a partir da zona desorganizada que constitui o núcleo do traço latente, o que conduz a formas de aparências tubulares; nos vidros, ela afeta mais sensivelmente o material são. Como conseqüência, nesses últimos materiais, uma película superficial é dissolvida e os traços apresentam uma morfologia diferente, seja circular (traços perpendiculares à superfície), seja mais ou menos elíptica (conforme sua obliqüidade sobre esta superfície) (Fig. 4). Por outro lado, não é o percurso total dos fragmentos de fissão que pode assim ser revelado. Os últimos dois micra de fim de percurso, lá onde os danos de irradiação são menos intensos, permanecem sempre aquém do domínio do visível. Trata-se da relação entre a zona mais danificada (electronic stopping power) e a zona menos danificada (nuclear stopping power) de traços de fissão. A observação dos traços de fissão sendo sempre praticada por microscopia óptica em transmissão, a datação TF se aplica assim em minerais e vidros transparentes, ou que, como no caso da obsidiana, tornam-se transparentes quando em finas espessuras. $\mathrm{Na}$ figura 5 observa-se o aspecto 'cometa' dos traços nos minerais, um efeito óptico devido à reduzida profundidade do campo de magnificação utilizada de 1250x. Na obsidiana, a presença de traços muito arredondados com outros muito mais finos é devida ao comportamento deste material descrito na figura 4, precedente: os traços mais finos são os últimos a terem tido contato com o 


\section{A Traços latentes}
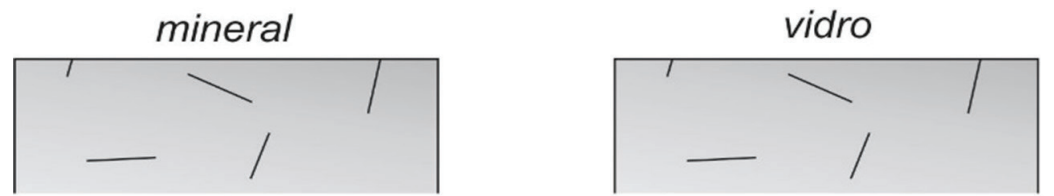

B Traços revelados
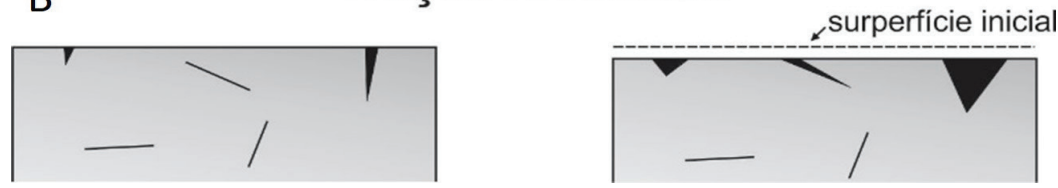

Figura 4. Esboços ilustrando a influência, sobre a morfologia dos traços, da velocidade relativa de dissolução ao longo dos traços latentes e em uma superfície não perturbada. A) Traços latentes em mineral (esquerda) e em vidro (direita). B) Traços revelados em mineral (esquerda) e em vidro (direita). A diferença entre minerais e vidros é devida a maior reatividade destes últimos em relação à solução utilizada para a revelação dos traços. A própria superfície de observação dos traços revelados é igualmente o resultado da dissolução de uma fina película superficial.

Figura 4. Sketches illustrating the influence on tracks morphology of the relative velocity of dissolution along the latent tracks and on an undisturbed surface. A) Latent tracks in mineral (left) and glass (right). B) Echting tracks in mineral (left) and glass (right). The difference between minerals and glasses is due to the greater reactivity of the latter in relation to the solution used for tracks revelation. The observation surface of the revealed tracks is also the result of the dissolution of a thin surface film.

reagente devido a dissolução superficial do vidro, observada em magnificação 500x. Os traços mais longos medem em torno de 11 micra para o zircão; apresentam um diâmetro médio de 6,5 micra nas obsidianas.

\section{Derivação da equação da idade}

O número de átomos de ${ }^{238} \mathrm{U}$ que decaem por fissão espontânea é uma fração constante $\lambda_{f} / \lambda_{d}$ de todas as suas desintegrações naturais. Consequentemente, o número $N_{s}$ de traços de fissão espontânea acumulados por unidade de volume ao longo do tempo tem um volume compreendendo $\mathrm{N}_{238}$ átomos de ${ }^{238} \mathrm{U}$ será dado pela equação 1 .

$$
\mathrm{N}_{\mathrm{s}}=\frac{\lambda_{\mathrm{f}}}{\lambda_{\mathrm{d}}} \mathrm{N}_{238}\left(\mathrm{e}^{\lambda_{\mathrm{d}} \mathrm{t}}-1\right) \quad \text { [Eq. 1] }
$$

A densidade número. $\mathrm{cm}^{-2} \rho_{s}$ de traços de fissão suscetíveis de serem revelados na superfície de um mineral se expressa pela equação 2.

$$
\rho_{\mathrm{s}}=\mathrm{k}_{\mathrm{s}} \frac{\lambda_{\mathrm{f}}}{\lambda_{\mathrm{d}}} \mathrm{R}_{238} \mathrm{~N}_{238}\left(\mathrm{e}^{\lambda_{\mathrm{d}} \mathrm{t}}-1\right) \quad \text { [Eq. 2] }
$$

Onde:

$\lambda_{f}$ e $\lambda_{d}$ são respectivamente as constantes de decaimento por fissão espontânea e total $\left(\lambda_{d}=\lambda_{f}+\lambda_{\alpha}\right), \quad \lambda_{\alpha}$ a constante de decaimento por radioatividade $\alpha$;

$R_{238}$ : o percurso médio revelável de um fragmento de fissão e;

$\mathrm{k}_{\mathrm{s}}$ : fator de proporcionalidade que caracteriza a eficácia de contagem dos traços.

Este último parâmetro pode ser considerado como um fator experimental cujo valor depende dos protocolos de revelação dos traços e de seus critérios de reconhecimento. A constante de fissão espontânea sendo muito pequena face à constante de decaimento por radioatividade $\alpha$, considera-se que $\lambda_{\mathrm{d}} \approx \lambda_{\alpha}$ (Tab. 1). Os únicos trabalhos realizados para a determinação da constante de fissão espontânea $\lambda_{f}$ a partir de estudos de traços de fissão foram aqueles desenvolvidos por Hadler et al. (1981) e Guedes et al. (2000), cujos valores obtidos se

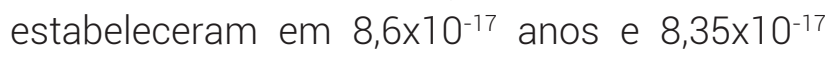
anos, respectivamente. Observa-se que estes valores são muito próximos do valor de consenso admitido pela comunidade científica atualmente que é de 8,5×10-17 anos. 

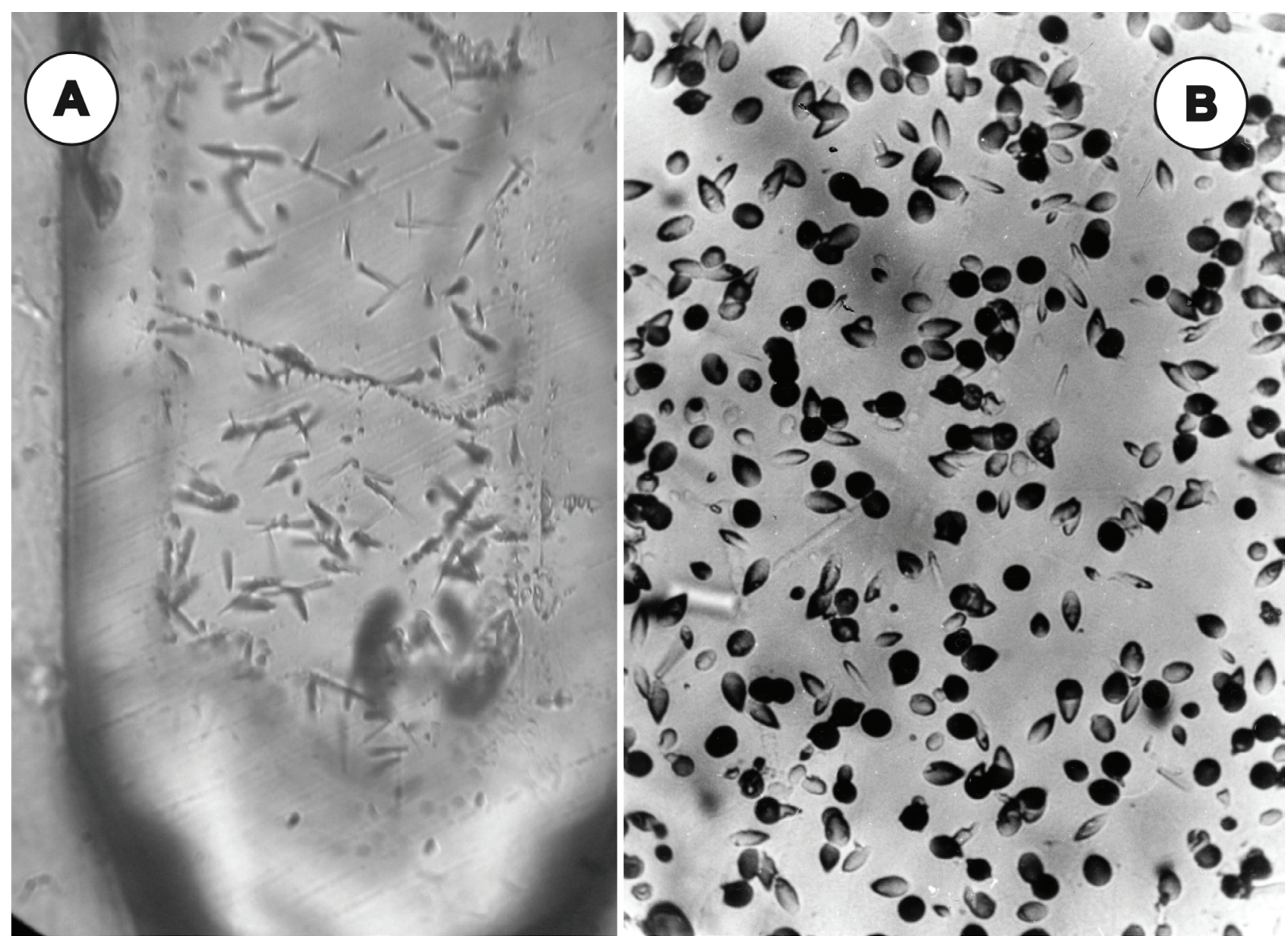

Figura 5. Traços de Fissão espontâneos de ${ }^{238} \mathrm{U}$ em um zircão (A) e traços de fissão induzida de ${ }^{235} \mathrm{U}$ em uma obsidiana (B). Os traços são observados em microscopia óptica em luz transmitida e magnificação de 500x. Condições de revelação: zircão, solução eutética de $\mathrm{NaOH}-\mathrm{KOH}$ à $220^{\circ} \mathrm{C}$ durante 48 horas (cliché G. Toro); obsidiana, solução de $\mathrm{HF} 20 \%$ a $40^{\circ} \mathrm{C}$ durante 120 segundos (cliché G. Bigazzi).

Figure 5. Spontaneous fission tracks of ${ }^{238} \mathrm{U}$ in a zircon $(A)$ and induced fission tracks of ${ }^{235} \mathrm{U}$ of an obsidian (B). The tracks are observed under optic microscopy with transmition light and magnification 500x. Etching conditions: zircon, $\mathrm{NaOH}-$ $\mathrm{KOH}$ eutectic solution at $220^{\circ} \mathrm{C}$ for 48 hours (figure by G. Toro); obsidian, HF solution $20 \%$ at $40^{\circ} \mathrm{C}$ for 120 secondes (figure by G. Bigazzi).

Tabela 1. Os isótopos naturais que fissionam espontaneamente 232Th, 238U e 235U.

Table 1. Natural isotopes that fission spontaneously 232Th, $235 \mathrm{U}$ and $238 \mathrm{U}$.

\begin{tabular}{|c|c|c|c|}
\hline Isótopo & $\lambda_{d}{ }^{*}$ & $\lambda_{\mathrm{f}}^{*}$ & $\tau * *$ \\
\hline${ }^{232} \mathrm{Th}$ & $1,4 \times 10^{-10}$ & $1,0 \times 10^{-21}$ & $<5 \times 10^{-5 * * *}$ \\
\hline${ }^{235} \mathrm{U} * * * *$ & $9,8 \times 10^{-10}$ & $1,0 \times 10^{-19}$ & $\approx 10^{-6}$ \\
\hline${ }^{238} \mathrm{U}$ & $1,5 \times 10^{-10}$ & $8,5 \times 10^{-17}$ & 1 \\
\hline \multicolumn{4}{|c|}{$\begin{array}{l}* \lambda_{\mathrm{d}} \text { e } \lambda_{\mathrm{f}} \text {, constantes de desintegração total e por fissão espontânea, } \\
\text { respectivamente. } \\
\tau * * \text { Taxa relativa ao }{ }^{238} \mathrm{U} \text { de produção de traços de fissão espontânea } \\
\text { durante o Plio-Quaternário. } \\
* * * \text { Calculada para uma razão Th/U=4 } \\
* * * *{ }^{235} \mathrm{U} /{ }^{238} \mathrm{U}=7,25 \times 10^{-3} .\end{array}$} \\
\hline
\end{tabular}


Por outro lado, em estudos do PlioQuaternário $\mathrm{t}<5,3 \mathrm{Ma}$, o termo exponencial se reduz à série $1+\lambda_{\alpha} t+\lambda_{\alpha} t^{2} / 2 !+\ldots .1+\lambda_{\alpha} t$. A equação 2 se reduz então a:

$$
\rho_{\mathrm{s}}=\mathrm{k}_{\mathrm{s}} \lambda_{\mathrm{f}} \mathrm{R}_{238} \mathrm{~N}_{238} \mathrm{t}
$$

Da mesma forma, após irradiação desse material por nêutrons térmicos em reator nuclear, a densidade de traços de ${ }^{235} \mathrm{U}$ que é possível revelar se expressa por:

$$
\rho_{\mathrm{i}}=\mathrm{k}_{\mathrm{i}} \mathrm{R}_{235} \mathrm{~N}_{235} \sigma \Phi \quad \text { [Eq. 4] }
$$

Onde $\sigma$ e $\Phi$ são respectivamente a seção de captura de um nêutron termal por um átomo de urânio 235 e a fluência nêutrons. $\mathrm{cm}^{-2} \cdot \mathrm{sec}^{-1}$ utilizada. A combinação das equações [3] e [4] fornece uma primeira forma da equação da idade:

Onde:

$$
\mathrm{t}=\mathrm{g} \frac{\sigma \mathrm{I} \Phi}{\lambda_{\mathrm{f}}} \frac{\rho_{\mathrm{s}}}{\rho_{\mathrm{i}}}
$$

$k=k_{i} / k_{s}=1 \quad$ em dadas condições experimentais e I expressa a razão isotópica $\mathrm{N}_{235} / \mathrm{N}_{238} \mathrm{l}=7,2527 \times 10^{-3}$.

A energia de fissão e as massas dos fragmentos de fissão espontânea de ${ }^{238} \mathrm{U}$ e induzida de ${ }^{235} \mathrm{U}$ sendo muito próximas, $R_{238}=R_{235}=1$. O surgimento do parâmetro $g$ está associado à geometria das superfícies de contagem dos traços; $g=1$ quando traços de fissão espontâneo e induzido são determinados nas superfícies internas obtidas por polimento, e 0,5 para a técnica do detetor externo (ver adiante). A medida absoluta das fluências de nêutrons termais pode ser realizada diretamente através da medida da radioatividade induzida em monitores constituídos de fios ou de pastilhas de ouro ou de cobalto irradiados com as amostras a serem datadas (Van den Haute et al., 1988; Wagner \& Van den Haute, 1992). Entretanto, na maioria dos laboratórios, utilizam-se, por comodidade, dosímetros de vidro dopados com urânio. A densidade de traços de fissão induzida $r_{d}$ que se pode revelar é proporcional à fluência segundo a equação 6:

$$
\Phi=B \rho_{d}
$$

[Eq. 6]

Onde B é uma constante. Assim, a equação da idade se escreve sob uma outra forma operacional:

$$
t=g \frac{\sigma I B}{\lambda_{f}} \frac{\rho_{s}}{\rho_{i}} \rho_{d}
$$

A obtenção de uma idade TF é adquirida por meio de três contagens de traços em microscopia óptica. A utilização da equação 7 repousa sobre uma calibração do parâmetro B da equação 6, a partir de uma irradiação, ou de uma série de irradiações cuja dosimetria é determinada de maneira independente. A dosimetria neutrônica é obtida com o uso de vidros dopados em urânio e filmes finos ou por ativação neutrônica. Um trabalho mais recente mostra que ambas as dosimetrias são precisas e equivalentes (Soares et al., 2014). Para compensar um eventual erro na dosimetria neutrônica, a constante de fissão espontânea $\left(\lambda_{f}\right)$ pode então ser considerada na equação 7 como um parâmetro independente cujo valor é ajustado a partir da 'datação' de amostras de referência de idade $\mathrm{t}$ conhecida através de outros métodos isotópicos (ver entre outros Wagner \&Van den Haute, 1992; Bigazzi et al., 2005b; McDowell et al., 2005). Disto resulta a variabilidade dos valores de $\lambda_{f}$ utilizados no passado. Os padrões utilizados são rochas vulcânicas que não sofreram nenhuma influência térmica desde sua erupção.

A equação da idade também pode ser escrita, agrupando o conjunto de suas constantes, sob uma forma mais condensada (Eq. 8).

$$
\mathrm{t}=\mathrm{g} \zeta \frac{\rho_{\mathrm{s}}}{\rho_{\mathrm{i}}} \rho_{\mathrm{d}}, \operatorname{com} \zeta=\frac{\sigma \mathrm{IB}}{\lambda_{\mathrm{f}}} \quad \text { [Eq. 8] }
$$

A vantagem em escrever a equação desta forma (Fleischer \& Hart, 1972) surge imediatamente. Basta calibrar o parâmetro $\zeta$ zeta, para determinadas condições de análise, a partir de amostras de idades conhecidas, sem haver necessidade de fazer hipóteses sobre o valor real das constantes utilizadas e a equação permite eliminar qualquer medida de 
dosimetria neutrônica. Cabe salientar que ろ é um parâmetro específico de cada analista cujo valor é estabelecido pela acurácia na contagem dos traços espontâneos e induzidos da amostra padrão. Este procedimento é análogo àquele utilizado para as datações por ${ }^{40} \mathrm{Ar} /{ }^{39} \mathrm{Ar}$ (Dickin, 1995).

A exatidão de uma idade TF depende, portanto, antes de tudo, das exatidões das datações isotópicas realizadas em amostraspadrão, que podem ser estimadas em $2-3 \%$. A precisão sobre os parâmetros $B$ da equação [7] e $\zeta$ da equação [8] se situa em geral, conforme os laboratórios, em torno de 1-2\%. A precisão sobre uma idade TF se deduz das incertezas sobre a medida das densidades de traços segundo a equação 9.

$$
\frac{\sigma \mathrm{t}}{\mathrm{t}}=\sqrt{\left(\frac{\sigma \rho_{\mathrm{s}}}{\rho_{\mathrm{s}}}\right)^{2}+\left(\frac{\sigma \rho_{\mathrm{i}}}{\rho_{\mathrm{i}}}\right)^{2}+\left(\frac{\sigma \rho_{\mathrm{d}}}{\mathrm{d}}\right)^{2}}
$$

[Eq. 9]

Nos vidros, como nas obsidianas ou aqueles utilizados em dosimetria neutrônica, onde a distribuição do urânio é homogênea, a distribuição das contagens de traços é poissoniana, e a equação [8] se reduz na equação 10.

$$
\frac{\sigma \mathrm{t}}{\mathrm{t}}=\sqrt{\frac{1}{\mathrm{~N}_{\mathrm{s}}}+\frac{1}{\mathrm{~N}_{\mathrm{i}}}+\frac{1}{\mathrm{~N}_{\mathrm{d}}}}
$$

Onde $N_{s^{\prime}} N_{i}$ e $N_{d}$ são respectivamente os números de traços fósseis e induzidos da amostra a ser datada e o número de traços induzidos associados ao dosímetro.

Como a precisão sobre $\rho_{\mathrm{i}}$ e $\rho_{\mathrm{d}}$ pode facilmente ser reduzida a $2 \%$, às vezes até menor, a precisão sobre uma idade TF plioquaternária repousa essencialmente sobre o número relativamente menor de traços fósseis que podem ser contados. O 'método absoluto' da equação [7] foi geralmente utilizado até os anos 1980, a partir dos quais foi rapidamente eliminado, para os minerais, em proveito da 'calibração zeta' da equação [8]. O único domínio em que ele verdadeiramente tenha perdurado é aquele da datação de vidros entre outros (Bonetti et al., 1998; Dorighel et al., 1998; Bigazzi et al., 2008), embora a equivalência entre os dois métodos tenha sido demonstrada (Balestrieri et al., 1998).

\section{A datação das obsidianas}

As obsidianas estão entre as rochas vulcânicas mais ricas em silica $(>65 \%$ em massa). Elas são a contrapartida 'vítrea' dos riolitos, formas 'vitrofíricas" de um mesmo magma, todos os termos intermediários entre estes dois extremos podem existir. A fase vítrea das obsidianas geralmente contém de 3 a 5 ppm de urânio, mas pode atingir uns 15 ppm, como aquelas da ilha de Lipari, ao norte da Sicília.

Encontra-se poucas obsidianas anteneógenas (>34 Ma), devido a desvitrificação que afeta sua matriz vítrea. Nestas condições as densidades de 'traços fósseis' que elas contém, ou seja oriundas da fissão espontânea, quase sempre são inferiores a $10^{4}$ por $\mathrm{cm}^{2}$. Em contrapartida, as densidades de traços induzidos são em geral da ordem de 1 a $3 \times 10^{5}$ por $\mathrm{cm}^{2}$ conforme a escolha da fluência, ou seja de 10 a 30 vezes mais elevadas. Como por outro lado a repartição do urânio nesses vidros é muito homogênea, para a datação por TF as densidades de traços fósseis e induzidos são determinadas sobre dois fragmentos diferentes. Sabendo que o fragmento irradiado em reator terá uma densidade de traços $\rho_{\text {irr }}=\rho_{s}+\rho_{\mathrm{t}^{\prime}}$ as equações da idade 7 e 8 tornam-se (Eq. 7' e 8'):

$$
\begin{aligned}
& \mathrm{t}=\mathrm{g} \frac{\sigma \mathrm{IB}}{\lambda_{\mathrm{f}}} \frac{\rho_{\mathrm{s}}}{\rho_{\text {irr }}-\rho_{\mathrm{s}}} \rho_{\mathrm{d}} \\
& \mathrm{e} \\
& \mathrm{t}=\zeta \frac{\rho_{\mathrm{s}}}{\rho_{\text {irr }}-\rho_{\mathrm{s}}} \rho_{\mathrm{d}}
\end{aligned}
$$

As equações da idade $7^{\prime}$ e 8' sempre admitem que $R_{235}=R_{238}$, o que foi efetivamente verificado no caso de registro dos traços de fissão nos vidros (Bigazzi et al., 1991). Os traços fósseis e induzidos deveriam assim, nas 
obsidianas, apresentar a mesma distribuição de comprimentos. Ora, constata-se que isso é raramente observado. Se caracterizarmos, nos vidros, o tamanho de um traço pelo seu 'diâmetro', quer dizer, para aqueles que são elípticos (Fig. 5), pelo comprimento de sua corda maior, constatase, na maioria das vezes, uma distribuição dos 'diâmetros' dos traços fósseis claramente em decalagem para valores menores quando comparados com aqueles dos traços induzidos (Fig. 6). Neste caso, se $D_{s}$ e $D_{i}$ são os diâmetros médios dos traços fósseis e induzidos, a razão $\mathrm{D}_{\mathrm{s}} / \mathrm{D}_{\mathrm{i}}$ torna-se inferior a 1 e a idade aparente $t_{\text {app }}$ obtida não é mais aquela da colocação da obsidiana, mas uma idade inferior sem significado geológico. Dois métodos de correção dessas idades aparentes foram propostos, que repousam sobre três hipóteses: (i) o encurtamento dos traços fósseis é devido à uma reorganização parcial dos traços latentes, que altera sua eficácia de revelação seja $k_{s}<k_{i}$ (ii) pode-se obter efeitos similares em traços induzidos produzidos em reator nuclear através de tratamentos térmicos apropriados em laboratório, e (iii) sob a condição de que o encurtamento natural não atinja valores extremos, todos os traços fósseis são reveláveis. Até o presente momento a experiência não contrapôs essas condições.

\subsection{0 método da correção pelos diâmetros}

Neste método de Storzer \& Wagner (1969) procura-se determinar a perda de densidade de traços fósseis que corresponde ao encurtamento médio observado entre os traços fósseis e induzidos. Primeiramente se estabelece, a partir de diferentes aquecimentos térmicos de traços induzidos, uma curva de calibração entre as diminuições correlativas do diâmetro médio e da densidade revelável de traços induzidos produzidos em reator nuclear. Essas medidas são efetuadas em fragmentos de obsidiana aquecidos a uma temperatura suficientemente elevada tipicamente $500^{\circ} \mathrm{C}$ durante 2 horas antes da irradiação em reator nuclear para eliminar qualquer traço fóssil préexistente. $O$ valor da razão $D_{s} / D_{i}$ dessa obsidiana é então utilizado para estimar, com o auxílio da curva de calibração, a redução correspondente da razão $\rho_{s} / \rho_{i}$ (Fig. 7). Para uma determinada obsidiana, o método primeiramente necessita o estabelecimento de uma curva de redução correlativa das densidades e dos diâmetros de traços sob o efeito de uma série de tratamentos térmicos sucessivos, cada um correspondendo a um fragmento de obsidiana que não tenha sido reaquecida após sua irradiação. A razão das densidades de traços fósseis e induzidos $\rho_{\mathrm{f}} / \rho_{\mathrm{i}}$ da amostra a ser datada é então utilizada para determinar graficamente a perda correspondente $\eta$ sobre a densidade de traços fósseis. A idade TF 'corrigida' é então calculada segundo $\mathrm{t}_{\text {corr }}=\mathrm{t}_{\text {app }} / \eta$. O principal inconveniente desse método é que cada obsidiana apresenta características físico-químicas específicas e assim deveria-se estabelecer, em princípio, pelo menos uma parte dessa curva de calibração para cada amostra a ser datada.

\subsection{Método de correção pelas 'idades-plateaux'}

A correção pelas idades-plateaux (Storzer \& Poupeau, 1973) trata do restabelecimento da condição de aplicação das equações da idade $7^{\prime}$ e 8', quer dizer do restabelecimento da condição de aplicação de $D_{s} / D_{i} \equiv R_{238} / R_{235}=1$. Para isso, quando $D_{s} / D_{i}<1$, procede-se a uma série de tratamentos térmicos cujo objetivo é de conduzir progressivamente os traços fósseis e induzidos à mesma taxa de redução (Fig. 8). Nessas condições as duas distribuições de diâmetros tornam-se similares e re-encontramos a condição $D_{s} / D_{i}=1$. Na prática contenta-se de efetuar dois ou mais tratamentos térmicos, com o tempo de recozimento constante e com várias temperaturas suficientemente elevadas para atingir esta condição (Fig. 9). Paralelamente, as densidades de traços diminuem com a temperatura e quando a razão $D_{s} / D_{i}$ atinge a unidade, as idades TF atingem um valor estável, ou 'plateau' (Fig. 10).

O método de correção pelas idadesplateaux é mais rápido e tem maior precisão do que aquele dos diâmetros e será na maioria das vezes o mais escolhido, com exceção dos casos em que as densidades de traços fósseis são muito baixas, da ordem de algumas dezenas 

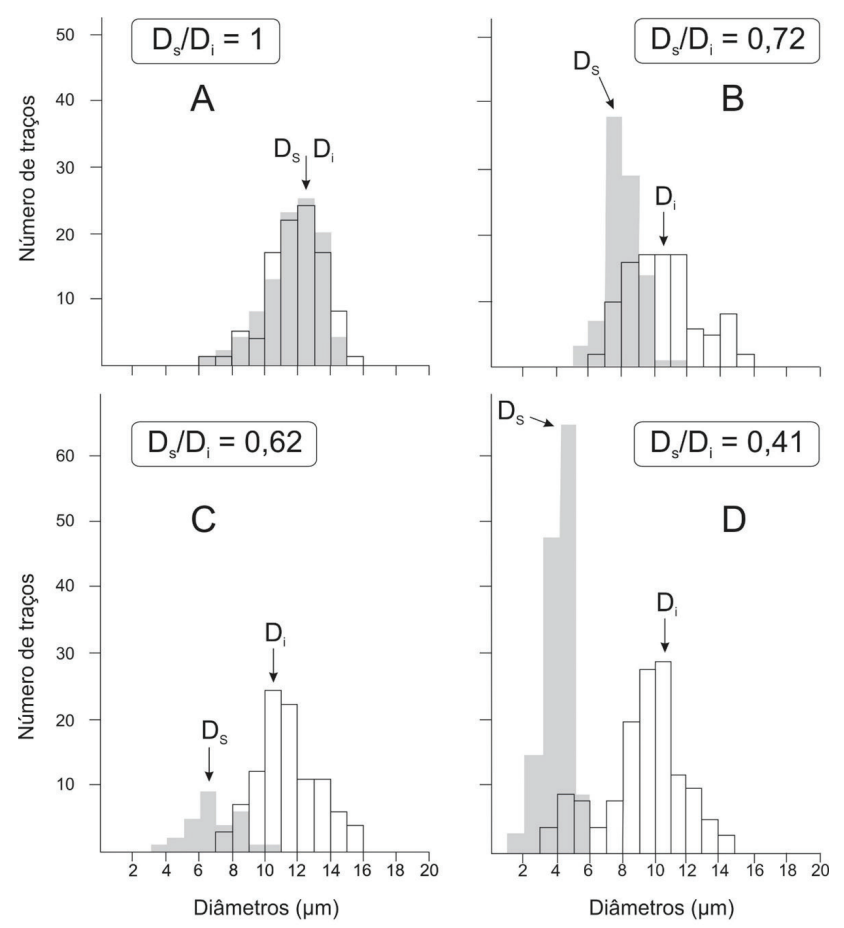

$D_{S}:$ traços espontâneos

$D_{\text {: }}$ : traços induzidos

Figura 6. Comparação entre os diâmetros dos traços fósseis e induzidos de algumas obsidianas do Mediterrâneo Ocidental. A) Traços fósseis de uma obsidiana da Ilha de Pantelleria, não há nenhum encurtamento em relação aos traços induzidos e a razão $D_{s} / D_{i}$ dos diâmetros médios é igual a 1. Nas demais obsidianas, oriundas do Monte Arci Sardenha, observa-se diferentes graus de encurtamento caracterizados pelas razões dos diâmetros médios fósseis/induzidos; B) Ds/Di=0,72; em C) Ds/Di=0,62 e em D) $\mathrm{Ds} / \mathrm{Di}=0,41$ (segundo Arias et al., 1984).

Figure 6. Comparison between the diameters of spontaneous and induced tracks of some obsidians of the Western Mediterranean. A) spontaneous tracks of an obsidian of Pantelleria Island there is no shortening in relation to the induced tracks and the Ds/Di ratio of their average diameters is equal to 1. In the other obsidians, coming from Mount Arci (Sardinia), different degrees of shortening are observed characterized by the ratios of the spontaneous/induced average diameters; B) $D s / D i=0.72$ in C) $D s / D i=0,62$ and in $D$ ) $D s / D i=0,41$ (according to Arias et al., 1984).

de traços, como no caso de obsidianas formadas há menos de 10.000 anos. Atinge-se os limites da datação no que tange as idades recentes, em torno de 1.000 anos (Bigazzi \& Bonadonna, 1973; Virk et al., 1989) e as idades mais antigas determináveis dependendo unicamente dos efeitos da desestruturação da matriz vítrea propriamente dita.

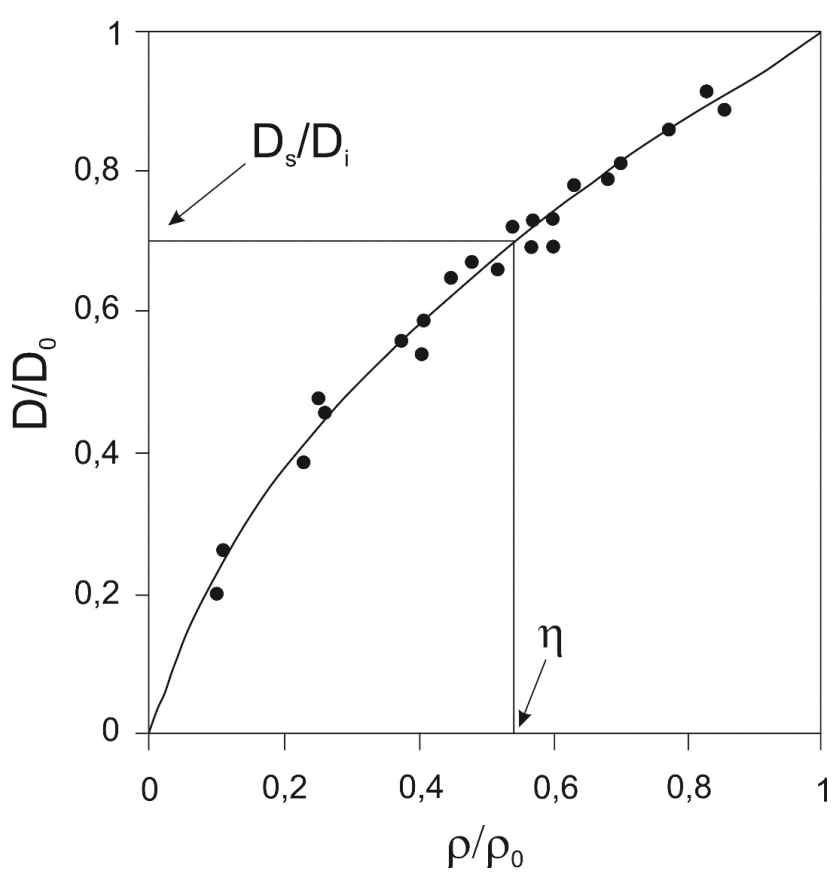

Figura 7. Método de correção das idades TF pelo método dos comprimentos dos traços, de Storzer \& Wagner (1969). Neste experimento, realisado com uma obsidiana do Monte Arci, as condições de revelação dos traços foram constantes, ou seja um ataque com HF $20 \%$ a $40^{\circ} \mathrm{C}$ durante 120 segundos (segundo Bigazzi \& Radi, 1981).

Figure 7. Method of correction of the FT ages by the method of lengths tracks of Storzer \& Wagner (1969). In this experiment, realised with an obsidian of Mount Arci, the etching conditions of the tracks were constant, i.e. a track revelation with $\mathrm{HF} 20 \%$ at $40^{\circ} \mathrm{C}$ for 120 seconds (according to Bigazzi \& Radi, 1981).

\section{A datação das obsidianas e a pré-História}

A obsidiana foi considerada, entre as matérias primas, uma das preferidas da indústria lítica préhistórica Sendo material geológico, com efeito, ela pode ser trabalhada tanto em percussão quanto em pressão para a realização de uma grande variedade de artefatos. Ela permite 


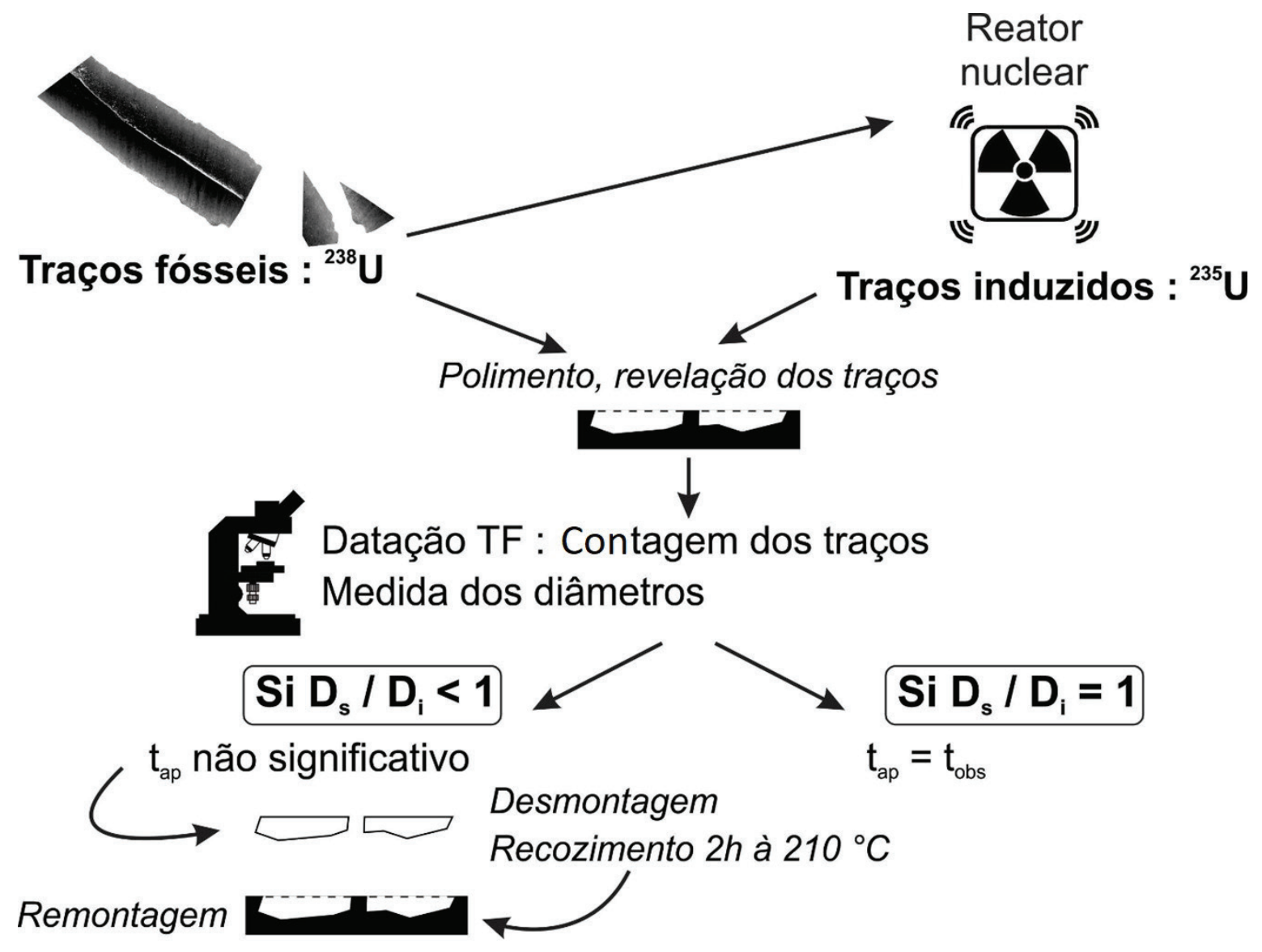

Polimento, revelação, medida dos diâmetros
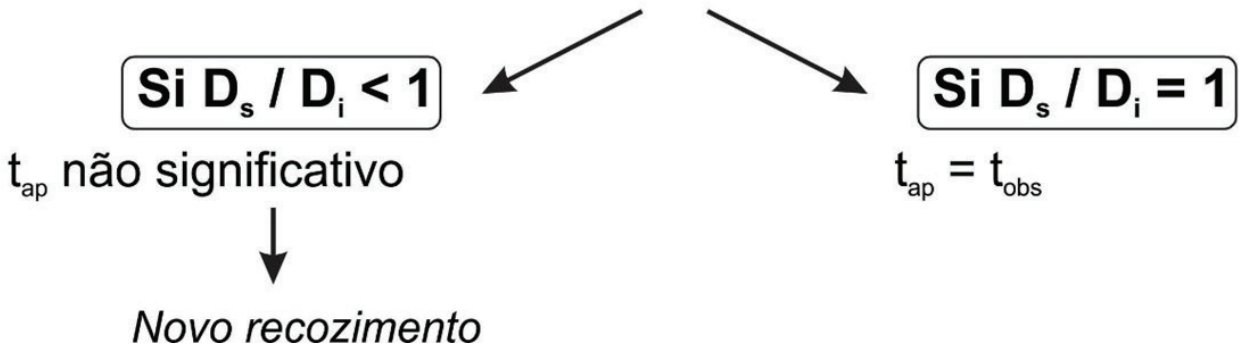

$t_{a p}=t_{o b s}$

Novo recozimento

Figura 8. Princípio do método de datação pelas 'idades-plateaux' de obsidianas ver texto (Segundo Poupeau et al., 1995). $T_{\text {app }}=$ idade aparente medida antes de qualquer tratamento térmico; $t_{o b s}=$ idade determinada após tratamento térmico. Esta idade se estabiliza quando $D_{s}=D_{i}$ ver figuras 9 e 10. Com as tefras, procede-se, para cada etapa com lotes de esquilhas que não tiveram nenhum tratamento térmico.

Figure 8. Principle of the step-heating plateau method of obsidians (see text) (According to Poupeau et al., 1995). $T_{\text {app }}=$ apparent age measured before any heat treatment; $t_{\text {obs }}=$ age determined after heat treatment. This age is stable when Ds=Di (see figures 9 and 10). With the tephras, it is carried out for each step with keel lots that had not yet been exposed to any heat treatment. 


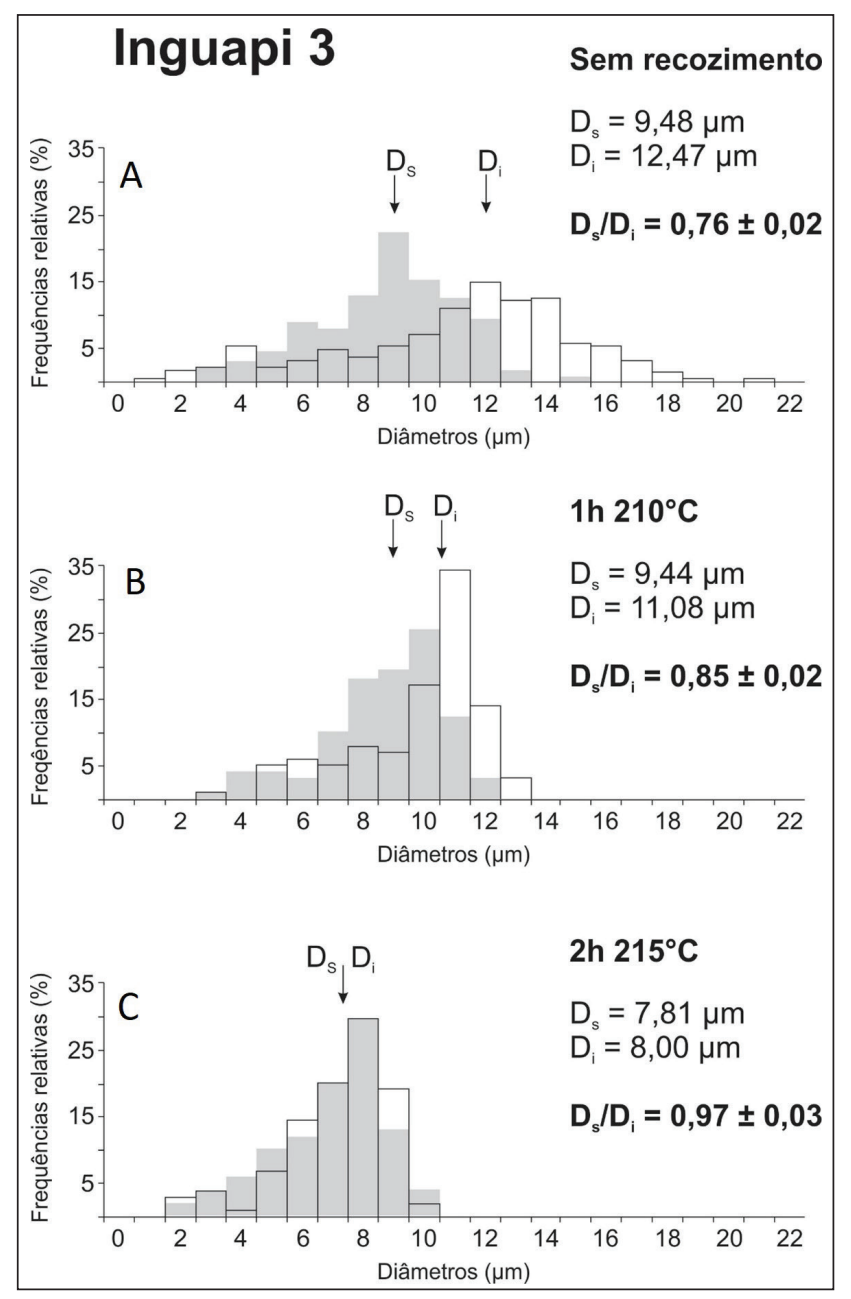

Figura 9. Evolução das distribuições dos diâmetros dos traços fósseis e induzidos de uma obsidiana do Equador após tratamentos térmicos, onde Ds e Di são respectivamente os diâmetros médios dos traços fósseis e induzidos. Em A, sem tratamento térmico, observa-se que os traços fósseis são em média mais curtos do que os traços induzidos, com $\mathrm{Ds} / \mathrm{Di}=0,76$. Em $\mathrm{B}$, após um primeiro tratamento térmico a $210^{\circ} \mathrm{C}$, são afetados principalmente os traços induzidos, a razão Ds/Di elevando-se a 0,85. Em $\mathrm{C}$, após um segundo tratamento de recozimento a $250^{\circ} \mathrm{C}$, as duas populações são atingidas e suas distribuições dos diâmetros tornam-se equivalentes, com Ds/Di=0,97 $\pm 0,03$ (segundo Poupeau et al., 2002).

Figure 9. Evolution of the distributions of the diameters of the fossil and induced tracks of an obsidian of the Equator after thermal treatments, where Ds and Di are respectively the average diameters of the spontaneous and induced tracks. In A, without heat treatment, it is observed that the fossil tracks are on average shorter than the induced tracks, with $(\mathrm{Ds} / \mathrm{Di})=0.76$. In $\mathrm{B}$, after a first heat treatment at $210^{\circ} \mathrm{C}$, the induced tracks are mainly affected, the (Ds/ Di) ratio rising to 0.85 . In $C$, after a second annealing treatment at $250^{\circ} \mathrm{C}$, the two populations are affected and their distributions of diameters become equivalent, and $(\mathrm{Ds} / \mathrm{Di})=0.97 \pm 0.03$ (according to Poupeau et al., 2002).

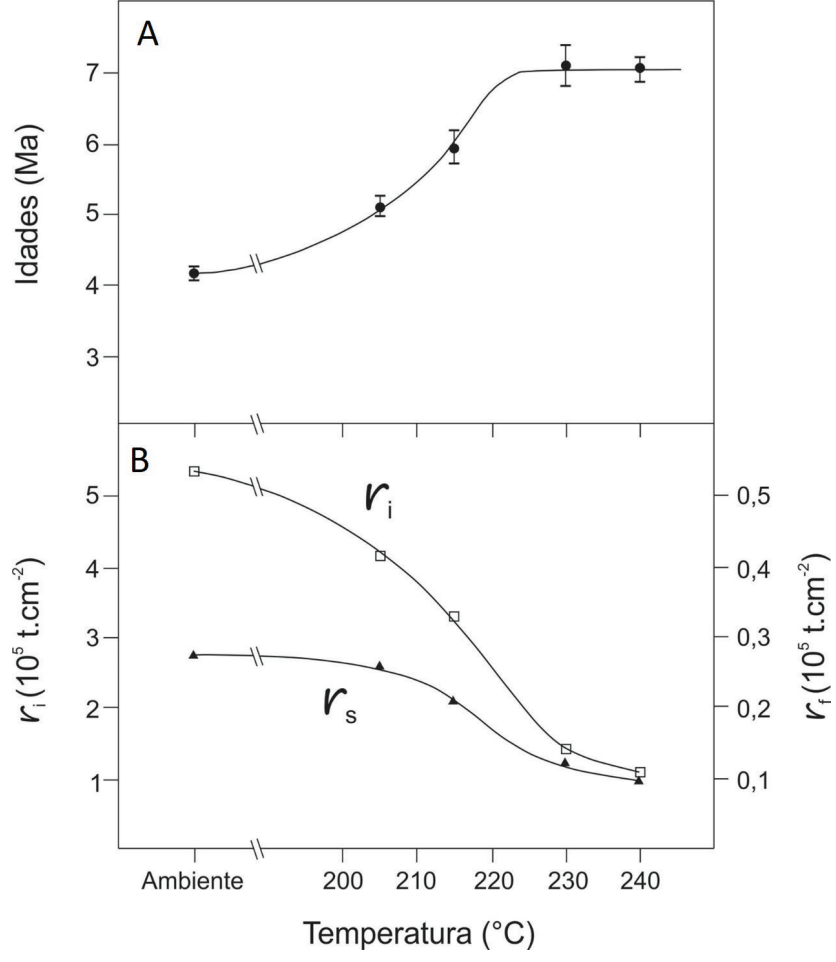

Figura 10. Evolução das densidades de traços e das idades TF de uma macusanita, obsidiana do Peru em função da temperatura, em uma datação pelo método 'idade-plateau'. A) Evolução das idades e B) evolução das densidades (segundo Poupeau et al., 1993).

Figure 10. Evolution of tracks densities and TT ages of a macusanita (obsidian) of Peru in function of temperature, in a dating by the method 'age-plateau'. A) Ages evolution and B) densities evolution. (according to Poupeau et al., 1993). 
obter, nas suas variedades mais vítreas, tanto peças com arestas cortantes excepcionalmente afiadas, quanto 'espelhos' com superfície polida refletora, como aqueles do sítio neolítico de Çatalhöyük (Turquia). É uma rocha que tendo sido explotada desde o Paleolítico Inferior, testemunhou rapidamente o deslocamento dos homens e a instauração das primeiras trocas em longas distâncias que acompanharam a neolitização.

A datação por TF pode fornecer dois tipos de informações sobre as relações entre o homem e a obsidiana. Permitindo obter a idade de formação de uma obsidiana 'arqueológica' ela oferece as chaves quanto a origem dessa matéria prima, entre as fontes vulcânicas que podem ser vislumbradas (Suzuki, 1969; Durrani et al., 1971; Arias-Radi et al., 1972). Mais raramente, quando um artefato foi levado ao fogo, intencionalmente ou não, à uma temperatura suficientemente elevada $\mathrm{T}>200^{\circ} \mathrm{C}$, é a idade do próprio objeto, ou mais precisamente é a data desse evento térmico que o afetou, que é determinada.

\subsection{Proveniência das obsidianas arqueológicas}

Os estudos de proveniência de obsidianas por TF foram efetuados principalmente no Japão (por exemplo, Suzuki, 1973; Koshimizu, 1981), do Mediterrâneo ao Transcáucaso e na América andina equatorial. Na segunda dessas regiões, os trabalhos foram executados sobre obsidianas neoliticas da bacia do Mediterrâneo (Durrani et al., 1971; Arias et al., 1984; Bigazzi \& Radi, 1998), da Europa central (Bigazzi et al., 1990), da Anatolia central e oriental (Yeğingil \& Göksu, 1982; Bigazzi et al., 1993, 1994, 1998) e da Armênia (Chataigner et al., 2003); na América do Sul, sobre as obsidianas arqueológicas pré-hispânicas do Equador e da Colômbia meridional (Miller \& Wagner, 1981; Bigazzi et al., 1992; Dorighel et al., 1998; Marcos et al., 1998; Bigazzi et al., 2005a). Na maior parte dessas regiões, as pesquisas de proveniência conduzidas pela análise por traços de fissão, como na Colômbia e no Equador, ilustrado na figura 11, foram completas e agora substituídas no Mediterrâneo ocidental por uma abordagem geoquímica. Os artefatos arqueológicos de obsidiana, de em torno de 50 sítios pré-hispânicos, foram caracterizados por traços de fissão e/ou em composição elementar (Bellot-Gurlet, 1998; Dorighel, 2000; Dorighel et al., 1998; Poupeau et al., 2002).

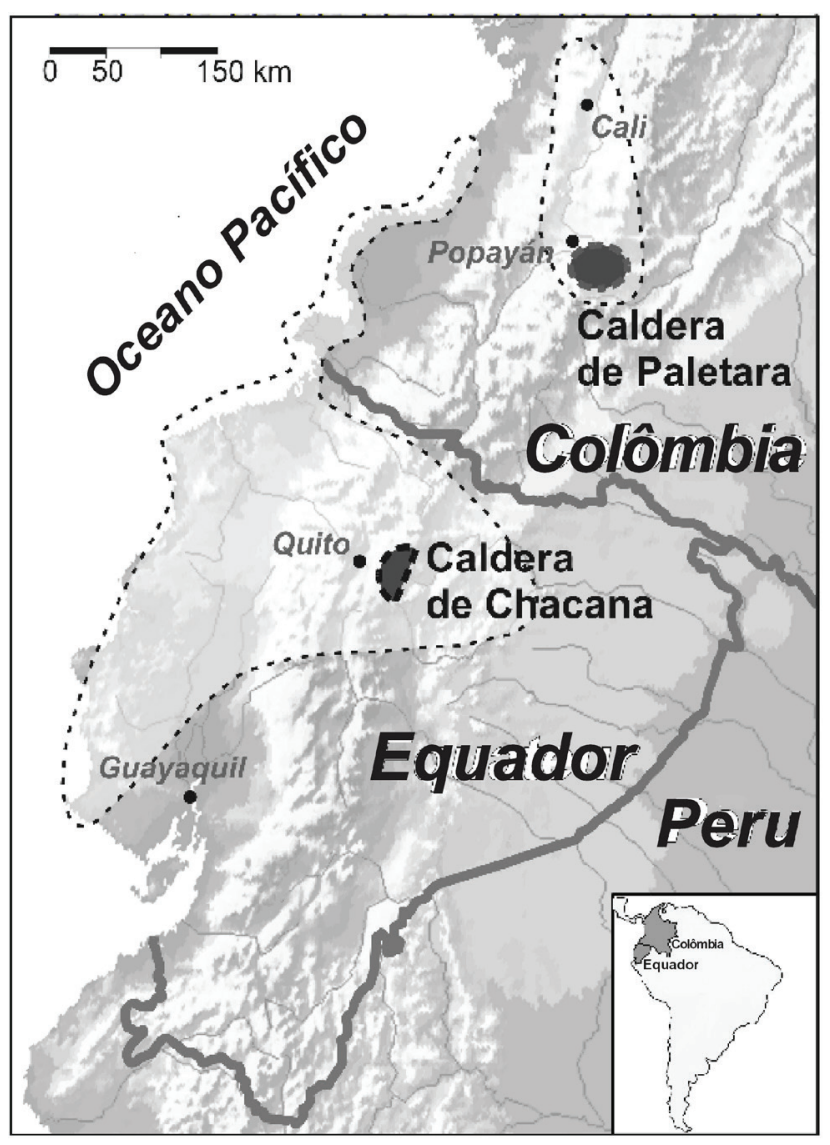

Figura 11. Mapa ilustrando as células de difusão antrópica (linhas tracejadas) das obsidianas associadas aos centros vulcânicos das calderas de Chacana no Equador e de Palétara (Colômbia).

Figure 11. Map illustrating the anthropic diffusion cells (traced lines) of obsidians associated with the volcanic centers of the calderas of Chacana (Ecuador) and of Palétara (Colombia).

Efetivamente, um certo número de dificuldades limitam a utilização do método dos traços de fissão. A primeira reside no fato de que nem todas as obsidianas servem para esses estudos. Se para a maioria dos casos as obsidianas utilizadas são suficientemente transparentes quando sua espessura é inferior à alguns milímetros, algumas variedades permanecem opacas mesmo abaixo dessa espessura, impedindo qualquer visualização dos traços. Em outros casos, a matriz vítrea pode conter um grande número de bolhas e/ ou cristálitos que limitam consideravelmente as 
observações, ou figuras de corrosão spurious tracks que surgem durante o ataque químico necessário para a revelação dos traços, ao ponto de tornar toda identificação duvidosa (Poupeau et al., 1998, Fig. 3). Também deve-se considerar que as obsidianas oriundas de diferentes fontes possam apresentar idades TF indistinguíveis. As razões $\rho_{i} / \Phi$ (equação 6 ou $\rho_{i} / \rho_{d}$ equação 8 ), proporcionais ao teor de urânio de uma obsidiana, podem então conduzir a uma tomada de decisão. Este foi o caso, por exemplo, no Mediterrâneo, onde as obsidianas das Ilhas de Milos e de Palmarola, apresentam idades TF quase concordantes de respectivamente 1,69 $\pm 0,10 \mathrm{Ma}$ e 1,57 $\pm 0,21 \mathrm{Ma}$, mas se diferenciam nos teores em urânio (Arias et al., 2006). Contrariamente, os traços são incapazes de diferenciar os quatro tipos de obsidianas do pequeno maciço cristalino do Monte Arci (Sardenha), sendo que elas são facilmente distinguiveis pelos teores em elementos maiores (Le Bourdonnec et al., 2006) e elementos traços (Le Bourdonnec et al., 2005; Lugliè et al., 2007). Enfım, dois últimos obstáculos se opõem a uma utilização predominante da datação TF em pesquisas futuras de proveniência, quais sejam: a exigência em materiaiseotempodasmedições, frequentemente proibitivos. De fato, a caracterização de uma obsidiana por traços requer duas plaquetas da ordem de $3 \times 3 \times 2 \mathrm{~mm}^{3}$, o que o torna um dos métodos mais consumidores em volume de amostra dentre o conjunto de métodos ditos destrutivos (Poupeau et al., 2007). Por fim, o tempo de aquisição dos dados, as medidas das densidades e dos diâmetros dos traços frequentemente é maior, podendo facilmente ultrapassar um dia inteiro para apenas uma obsidiana.

Entretanto há situações em que o método dos traços pode exercer um papel decisivo. Até o presente momento, embora existam muitas outras opções (Poupeau et al., 2007, 2008), os estudos de proveniência eram geralmente feitos por meio de métodos geoquímicos (Cauvin et al., 1998; Shackley, 1998). Excepcionalmente, há situações em que estes métodos não permitem distinguir as diversas origens das obsidianas, enquanto os traços o permitem. Um célebre exemplo na Anatólia oriental, é aquele das obsidianas percalcalinas de Çavuşlar et d'Orta Duz, nas proximidades de Bingöl, normalmente impossivel de serem distinguidas daquelas de Nemrut Dağ, vulcão situado à 80 $\mathrm{km}$ de distância. Essas obsidianas tiveram uma grande difusão antrópica durante o Neolítico no Oriente Próximo e no Oriente Médio e seria muito importante poder reconhecer de qual área-fonte provém a matéria-prima de um determinado artefato. Atualmente, a datação por TF é a única a proporcionar uma resposta sem anbiguidade, sendo as de Bingöl de idades pliocênicas, em oposição à idades inferiores à 40.000 anos para aquelas de Nemrut Dağ (Bigazzi et al., 1998; Bellot-Gurlet et al., 1999). Em um contexto diferente, a datação por TF de obsidianas arqueológicas da Colômbia e do Equador revelou a explotação de fontes ainda a serem descobertas (Dorighel et al., 1998; Poupeau et al., 2002). Inversamente, um conhecimento aprofundado das idades TF das fontes de uma província vulcânica pode propiciar a eliminação de algumas das áreas-fonte como recursos explotados no passado. Assim, a datação das três fontes de obsidianas em Lipari, indistinguivéis pela composição química, mostrou que apenas uma pode ser explotada durante o Neolítico, as duas outras sendo datadas somente do período histórico (Bigazzi \& Bonadonna, 1973).

\subsection{Datação de artefatos}

Em princípio, a datação de um artefato de obsidiana por TF é possivel se ele sofreu uma temperatura suficientemente elevada em um forno ou durante um incêndio, intencional ou não. Neste caso, tipicamente um aquecimento à $500^{\circ} \mathrm{C}$ durante 1 ou 2 horas é suficiente para a perda total dos traços de fissão espontâneos pré-existentes, e a idade TF data este evento (Fleischer et al., 1965c; Watanabe \& Suzuki, 1969; Wagner \& Van den Haute, 1992; Bellot-Gurlet et al., 1999). Condições menos extremas $T \leq 400^{\circ} \mathrm{C}$ podem produzir apenas um encurtamento mais ou menos importante dos traços e desta forma uma diminuição correlativa da densidade fossil $\rho_{\mathrm{s}}$. Eventualmente, em função da taxa de apagamento dos traços, pode-se observar uma distribuição bimodal dos diâmetros dos 
traços fósseis, os mais longos correpondendo àqueles produzidos entre este evento térmico e o presente (Miller \& Wagner, 1981; BellotGurlet et al., 1999). Neste caso, determina-se ao mesmo tempo a idade do recozimento e a idade da obsidiana. Assim, as duas populações de traços fósseis de um artefato colombiano, da figura 12, apresentam taxas de encurtamento de $74 \%$ e $11 \%$, respectivamente. Os traços mais curtos com diâmetros inferiores a 3,5 $\mu \mathrm{m}$ tiveram um encurtamento importante durante um evento térmico datado pelos raros traços mais longos, com diâmetros superiores a $4 \mu \mathrm{m}$, em torno de 3.400 anos. Salienta-se que mesmo esssa população de traços 'recentes' também sofreu um certo encurtamento, como pode ser observado no aumento x 50 da escala das ordenadas na parte direita da figura, onde a sua distribuição é comparada àquela dos traços induzidos revelados nas mesmas condições para este artefato. Uma correção pelo método dos diâmetros indica que se trata de uma obsidiana de $2 \mathrm{Ma}$, que sofreu um aquecimento importante há aproximadamente 3.400 anos, interpretada como sendo a idade de sua utilização pelo homem (Miller \& Wagner, 1981). Tais casos são excepcionais e permitem apenas datações com precisão limitada, e um custo em tempo de medida de densidade de traços fósseis, podendo exigir vários dias de contagem.

\section{Datação de Tefras}

Tefras são depósitos piroclásticos provenientes de manifestações vulcânicas do tipo plineano. No momento das 'explosões vulcânicas', grandes quantidades de partículas são ejetadas de 20 até $30 \mathrm{~km}$ de altura na atmosfera, que ao cairem rapidamente podem cobrir milhares de $\mathrm{km}^{2}$ formando camadas contínuas facilmente identificáveis em campo. Constituem-se assim em excepcionais marcadores estratigráficos, encontrados tanto nos continentes quanto em furos de sondagem oceânicos. As tefras são constituídas por mais de $90 \%$ de esquilhas de vidro glass shards. O complemento mineral das tefras pode conter anfibólios, felspatos, micas, quartzo, e mais raramente apatita, esfeno, zircão, etc, e encontram-se presentes principalmente

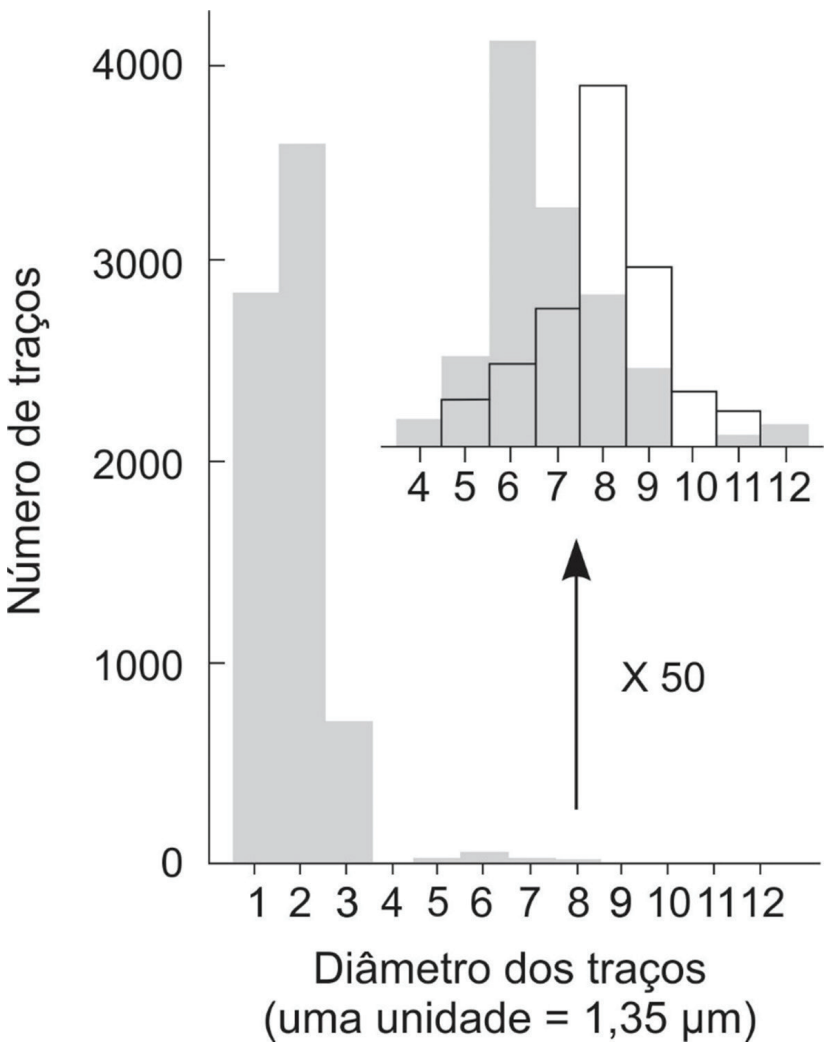

Figura 12. Distribuição dos diâmetros de traços fósseis em um artefato em obsidiana da Colômbia (segundo Miller \& Wagner, 1981).

Figure 12. Distribution of the diameters of fossil tracks in an obsidian artifact from Colombia (according to Miller \& Wagner, 1981).

nos depósitos proximais. A datação por TF das tefras se faz sobre as esquilhas de vidro ou nos minerais ricos em urânio, como apatita e o zircão.

\subsection{Datação em esquilhas de vidro}

A granulometria das esquilhas de vidro das tefras diminui progressivamente com a distância do centro de emissão. Geralmente elas têm uma dimensão submilimétrica e são as mais volumosas, entre 100 e 300 microns, que são utilisadas para a datação por TF, quando sua geometria o permite. Oriundas de um magma rico em voláteis e tendo ainda interagido com a atmosfera, elas podem, sem dúvida, ser extremamente vacuolares e não oferecerem superfícies adequadas para as contagens de traços. Estes vidros apresentam teores de urânio da ordem de apenas alguns ppm. Inclusive, numerosas esquilhas de tefras do plioquaternário não possuem nenhum traço fóssil. No entanto o que as torna datáveis por TF é a 
homogeneidade da distribuição de urânio e que por sua vez permitiu a introdução de uma técnica conhecida como contagem de pontos, através das medidas de densidades de traços (Naeser et al., 1982).

Numerosas esquilhas de vidro são inseridas em uma resina e polidas conjuntamente, utilizase um campo de visão de superfície constante para a contagem dos traços das esquilhas em toda a área da preparação. A superfície de cada campo sendo ocupada parcialmente pela esquilha e pela resina e a designamos por zero ou 1 caso seu centro esteja situado sobre o vidro ou não. A superfície total do vidro é estimada a partir da quantidade de "1" identificados. A densidade de traços é expressa segundo a equação $\rho=\mathrm{Nt} / \mathrm{Nc}$, onde $\mathrm{Nt}$ e $\mathrm{Nc}$ são respectivamente o número total $\mathrm{Nt}$ de traços contados em Nc campos de contagem. Convencionalmente, o diâmetro de observação sendo da ordem de grandeza de uma esquilha, utilisa-se sua superfície para transferir formalmente $r$ em traços $/ \mathrm{cm}^{2}$. Nesta técnica, diferentemente da datação das obsidianas, não se determina a área exata de contagem dos traços, ela introduz um erro adicional e a incerteza sobre uma densidade torna-se (Bigazzi \& Galbraith, 1999) segundo a equação 11.

$$
\frac{\sigma \rho}{\rho}=\sqrt{\frac{1}{N_{t}}+\frac{1-\frac{N_{c}}{n}}{N_{t}}} \quad \text { [Eq. 11] }
$$

onde n é o número de medidas pontuais.

De outra forma, na determinação de uma idade plateau, frequentemente utiliza-se temperaturas mais baixas - consequentemente com intervalos de recozimento mais longos que aquelas utilizadas para as obsidianas, isto para levar em conta a hidratação pósdeposicional das esquilhas de vidro. Efetivamente, um tratamento térmico com temperaturas $\geq 200^{\circ} \mathrm{C}$ provoca nas esquilhas de vidro hidratado, mudanças na estrutura que se traduzem por uma fraturação intensa quando da revelação dos traços (Naeser et al., 1980). Temperaturas mais baixas com durações de recozimento prolongadas permitem evitar efeitos deletérios (Poupeau, 1982). Atualmente, faz-se com frequência recozimentos da ordem de quinze a trinta dias a $150^{\circ} \mathrm{C}$ (Westgate, 1989; Sandhu et al., 1993; Westgate et al., 2001). O limite inferior da datação de esquilhas de tefras situa-se em torno de 50.000 anos, idade para qual ainda é possivel obter uma precisão de 15\% (Bigazzi et al., 2005a). Outras limitações surgem devido a morfologia das esquilhas (Fig. 13) ou, nas tefras distais, devido a suas dimensões muito reduzidas ou ainda em climas tropicais úmidos (Toro, 1999; Toro et al., 2006) com a sua transformação rápida em argilas. Em tefras pouco espessas, com frequência ocorre contaminações importantes devidas a materiais provindos de outras tefras por remobilização eólica, colúvios, águas de escoamento superficial e/ou fluviais, bioturbação, etc. Neste caso, para datá-las recorre-se a procedimentos que se aplicam a um monocristal, como a utilização de microclínio para as datações em ${ }^{39} \mathrm{Ar} /{ }^{40} \mathrm{Ar}$ ou a minerais acessórios ricos em urânio como apatita e zircão com TF, ou seja na pedra pomes. Neste último material, a datação pode ser obtida por TF nos zircões que são facilmente extraídos (Gleadow, 1980) ou ainda na matriz vítrea que as constitui. Sendo este vidro muito poroso a determinação das densidades de traços por contagem de pontos, assim como nas esquilhas, impõe-se na maioria das vezes.

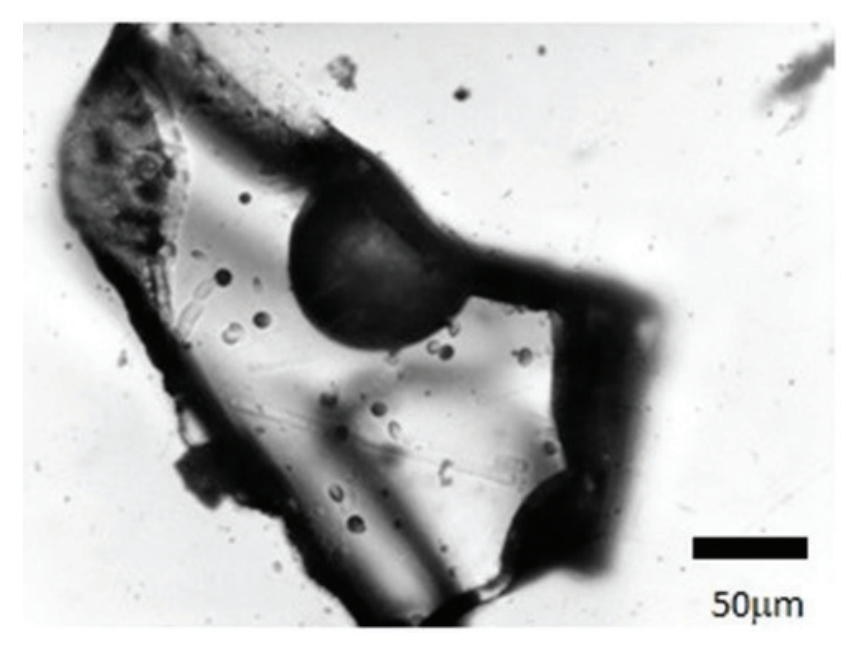

Figura 13. Traços de fissão induzida em uma esquilha de vidro extraída de uma tefra. 0 diâmetro médio dos traços é de 6,5 microns. As observações foram feitas em microscopia óptica em luz transmitida com um aumento de 500x (fotografia de G. Bigazzi).

Figure 13. Induced fission tracks in a glass shard extracted from a tephra. The average diameter of the tracks is 6.5 microns. These observations were made under optical microscopy in transmitted light with an increase of 500x (figure by G. Bigazzi). 


\subsection{Datação pelos minerais}

Duas propriedades dos minerais como apatita e zircão lhes permitem datar tefras e pedra pomes: o elevado teor em urânio e o fato de que nas temperaturas que vigoram próximo ou na superfície da terra, os traços de fissão são totalmente estáveis. Devido às características de revelação e de estabilidade dos traços, sempre serão escolhidas como áreas de contagem os planos de polimento paralelos ao eixo cristalográfico $C$ dos minerais, o que é facilitado pelas suas morfologias prismáticas muito características. Uma outra forma mais robusta de identificar a face paralela ao eixo $C$ dos minerais é com o uso da luz refletida. De fato, a observação em luz refletida da intersecção do traço de fissão com esta face do mineral mostra figuras típicas, que só se observam quando paralelas ao eixo C. Os zircões apresentam teores em urânio da ordem da centena a vários milhares de ppm, muito superiores àqueles dos vidros vulcânicos. Nas tefras se apresentam tipicamente sob a forma de prismas quadráticos bipiramidados cujo comprimento atinge no máximo algumas centenas de microns. Na datação por TF, utilizase apenas os grãos maiores do que 80 microns e cujas faces do prisma apresentam uma largura que permite evitar efeitos "de borda", ou seja, evitar os traços que poderiam provir de fissões de átomos de urânio situados na superfície ou na proximidade imediata, na ganga vítrea (pomes) ou no material tefrítico que os rodeava. Na contagem dos traços, será evitada uma banda periférica - como para as esquilhas de vidro- de uma dezena de microns (ou seja, superior ao percurso máximo de um fragmento de fissão), o que na prática tende a eliminar cristais cuja largura dos lados do prisma é inferior a 30-40 microns. As etapas a serem seguidas na datação de zircões são descritas na figura 14. Os traços induzidos correspondentes a um zircão são registrados e em seguida revelados, em um 'detetor externo' mantido em contato com o zircão ao longo da irradiação. Exige-se dos detetores de traços uma boa qualidade de registro e de establidade de traços de fissão. Eles não devem conter urânio (folhas de plástico como o kapton) ou conter apenas uma quantidade negligenciavel de urânio em comparação com o teor do mineral a ser datado como a mica muscovita onde o teor de $U$ pode ser inferior à uma dezena de ppb (ou seja, mais que $10^{4}$ menor do que aquele do zircão). Quando isto é possível, faz-se o polimento de um conjunto de pelo menos 20 cristais de zircão, e cada um fornece uma idade TF. As menores idades que se pode determinar com esses minerais se situariam, em condições favoráveis, em torno de 0,1-0,2 Ma (Nishimura, 1980).

Em uma tefra não perturbada, todos os minerais datados devem apresentar, para uma dada fluência neutrônica, o mesmo valor da razão $\rho_{\mathrm{s}} / \rho_{\mathrm{i}}$ equações 7 e 8 . Em um diagrama de comparação do número de traços fósseis e induzidos em cada grão datado, todos os pontos devem alinhar-se, considerando as incertezas estatísticas, sobre uma reta passando pela origem e cuja inclinação depende da idade da tefra. A dispersão dos pontos ao longo da reta depende da variação dos teores em urânio de cada um dos grãos figura 15a. A unicidade de uma população de idades pode ser verificada por um teste de $\chi^{2}$ no qual os números $\mathrm{N}_{\mathrm{s}, \mathrm{j}}$ e $\mathrm{N}_{\mathrm{i}, \mathrm{j}}$ de traços fósseis e induzidos por grão são comparados com aqueles esperados para uma distribuição cujos valores médios são aqueles destas contagens (Galbraith, 1981 ; Green, 1981). A probabilidade $P\left(\chi^{2}\right)$ calculada para um grau de liberdade $n=$ n-1 onde n é o número de grãos datados é então superior a 5\%. A equação da idade de um grupo de cristais de zircão pertencentes a uma mesma população torna-se conforme a equação 12.

$$
t=\zeta \frac{\Sigma N_{s, j}}{\Sigma N_{i, j}} \rho_{d}
$$

Em uma tefra retrabalhada estão presentes minerais provindos de vários eventos de idades diferentes, então $P\left(\chi^{2}\right)$ se torna inferior a $5 \%$. Eventualmente, várias populações de idades podem ser definidas (Galbraith \& Green, 1990; Brandon, 1992, 1996; Galbraith \& Laslett, 1993). Entretanto, em todos os casos a isócrona de referência correspondente à população de idades mais jovens e para a qual $P\left(\chi^{2}\right)$ ainda é superior a $5 \%$, fornece um limite superior para a idade desta tefra (Fig. 15b) (Brandon, 1992). 


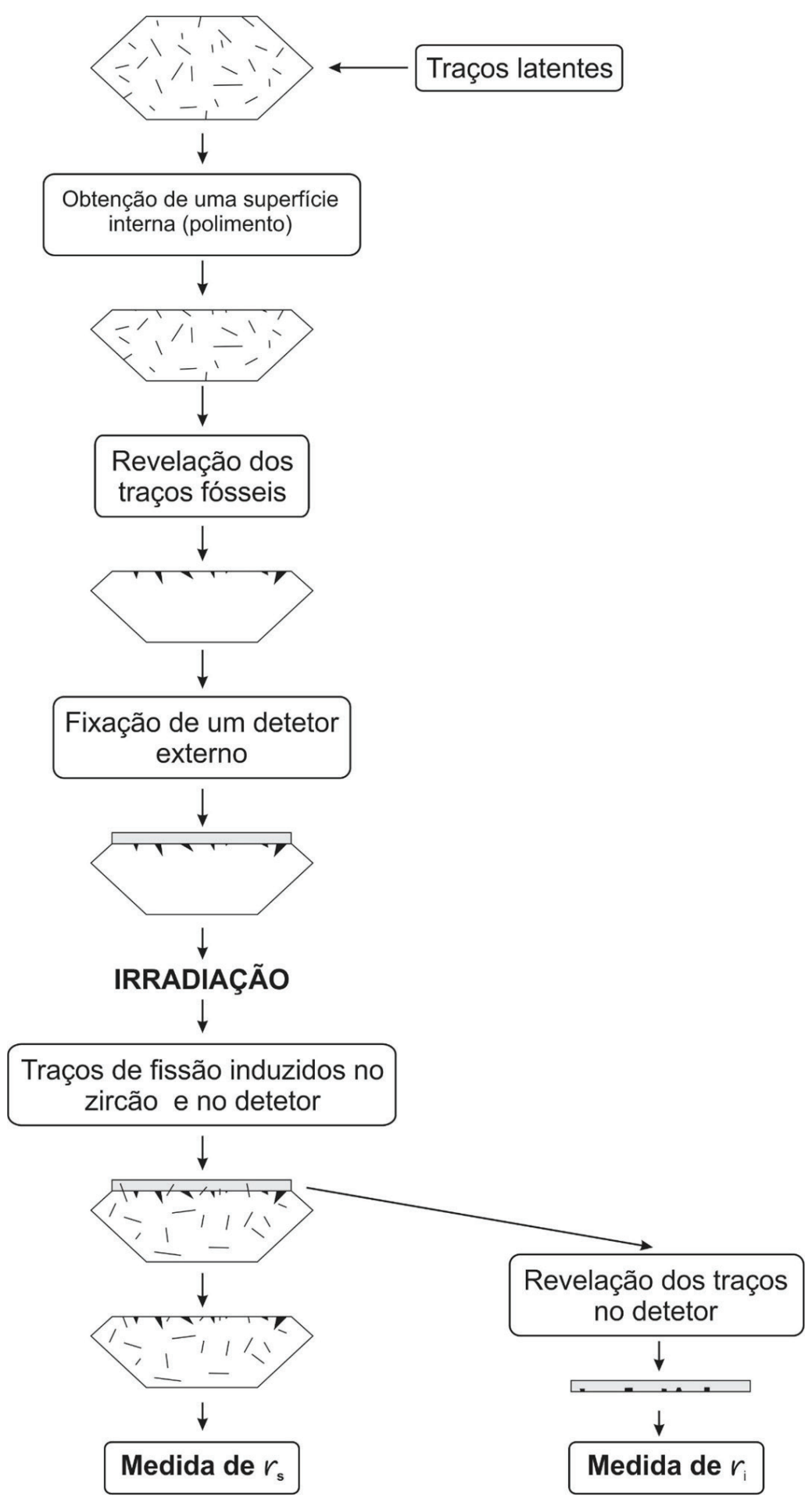

Figura 14. Sucessão das etapas a seguir para a obtenção das densidades de traços fósseis e induzidos $\rho_{\mathrm{s}}$ e $\rho_{\mathrm{i}}$ para a datação de zircão (segundo Toro, 1999 e Poupeau et al., 2002).

Figure 14. Succession of the steps to be followed to obtain the densities of fossil and induced tracks $\left(\rho_{s}\right.$ et $\left.\rho_{\text {) }}\right)$ in the zircon dating (according to Toro, 1999 and Poupeau et al., 2002). 
A representação dos dados em um diagrama isócrono valoriza o número de traços fósseis e induzidos utilizado para cada zircão. Por vezes prefere-se substituí-lo por um "diagrama radial" (Galbraith, 1990), que permite comparar diretamente as idades individuais de cada grão e sua precisão em relação a uma idade de referência, que pode ser a idade TF das equações 7 e 8. Este tipo de diagrama salienta a unicidade ou não da população de idades presentes em um grupo de zircões. Na figura 16 a localização de cada ponto representativo de um zircão depende de sua idade e de sua precisão. Assim o zircão de 13,5 Ma tem seu ponto representativo
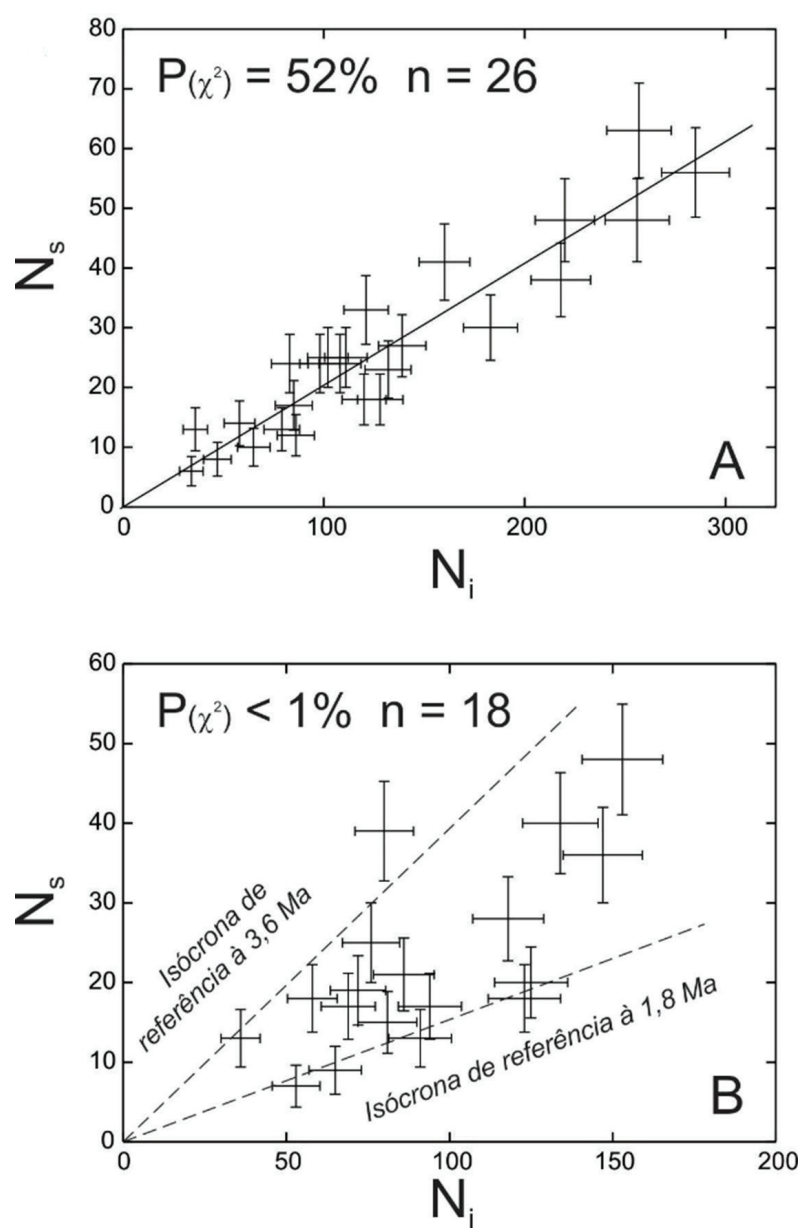

Figura 15. Representação isócrona dos dados TF para a datação de zircões plio-Quaternários da Colômbia Central. A) Tefra primária não retrabalhada; B) Tefra retrabalhada contendo zircões vulcânicos de diferentes idades plioquaternárias. $\mathrm{N}_{s}$ e $\mathrm{N}_{i}$ são respectivamente número de traços fósseis e induzidos em cada grão datado (segundo Toro, 1999).

Figure 15. Isochronous representation of FT data for the dating of plio-Quaternary zircons from Central Colombia. A) Primary tephra not reworked; B) Reworked tephra containing volcanic zircons of different plio-quaternary ages. $N_{s}$ and $N_{i}$ are respectively the number of fossil and induced tracks in each dated grain (according to Toro, 1999). situado sobre um raio que passa pela origem das ordenadas em uma escala logarítmica das idades, sua posição dependendo da precisão da idade. Na abcissa, a escala das precisões é dada pelo inverso da precisão relativa sobrea idade, $1 /(\sigma t / t)$. A escala $[+2,-2]$ das ordenadas corresponde à precisão da 'idade central' calculada considerando o conjunto dos grãos dessa tefra, neste caso de 7,3 Ma. A idade de referência versus a abcissa sobre o eixo dos log t é fixada pelo analista. Não se trata necessariamente da idade TF do conjunto de grãos datados. No presente caso, três populações de idades podem ser discriminadas, que são repectivamente 0,5

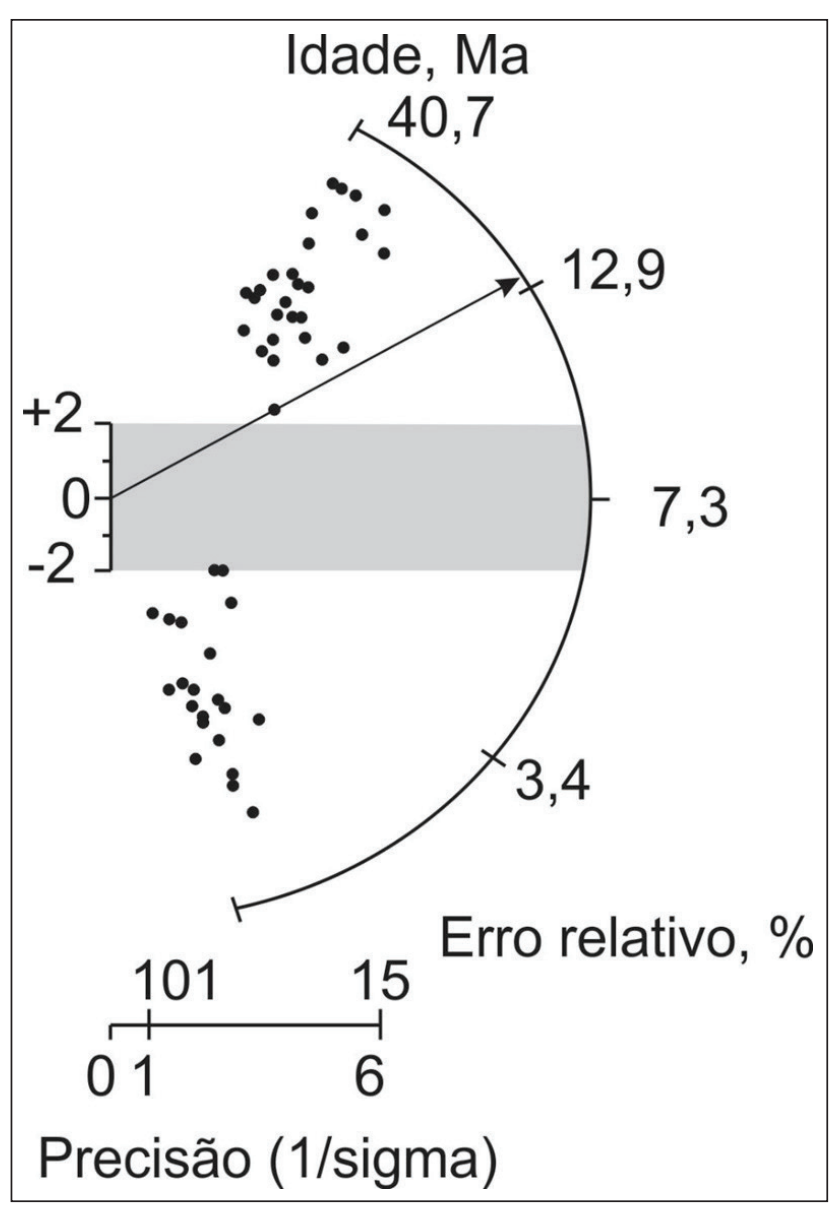

Figura 16. Representação por meio de um diagrama radial das idades TF determinadas em 52 zircões extraídos de uma tefra da Colômbia Central.

Figure 16. Representation by a radial diagram of the FT ages determined in 52 zircons extracted from a tephra from Central Colombia. 
Ma (21 grãos), 3,1 Ma (3 grãos) para os zircões automorfos de origem vulcânica, e de 13,5 a 41 Ma (28 grãos) para os zircões do embasamento cristalino (segundo Toro, 1999). A unicidade das idades pode igualmente ser ilustrada por diagramas de densidade de probabilidade de repartição de idades, como aqueles de Hurford et al. (1984) ou de Brandon (1992, 1996) (Fig 17).

As apatitas de dimensões aceitáveis para a datação por TF são muito menos frequentes que os zircões nas rochas vulcânicas piroclásticas e seus teores em urânio são sensivelmente inferiores àqueles dos zircões, pois situam-se em algumas dezenas de ppm. Assim elas são raramente datadas (mas há exceções - ver, por exemplo, Bigazzi etal., 2000; Marcolini etal., 2003). As apatitas apresentam em geral uma distribuição em urânio relativamente homogênea em cada cristal e teores pouco diferenciados entre os grãos. Para uma tefra não retrabalhada, pode-se datar as apatitas acumulando o número de traços fósseis e induzidos contados em grande número de grãos, para a determinação de $\rho_{\mathrm{s}}$ e de $\rho_{i^{\prime}}$ método conhecido como de 'populações' (Wagner \& Van den Haute, 1992). Neste caso não se pode- mais considerar que a dispersão das medidas é poissoniana, como para os zircões, nos quais determina-se o conjunto de traços fósseis e induzidos para cada grão individual, ou os vidros, onde a distribuição de urânio é homogênea. A incerteza relativa sobre as densidades de traços fósseis e induzidos é então calculada pela razão $\sigma / \mathrm{N}$, onde $\mathrm{N}=\sum \mathrm{Nj} / \mathrm{n}$ é o valor médio do número de traços $\mathrm{Nj}$ de cada grão, n o número de grãos contados e $\sigma$ o desvio-padrão da distribuição dos Nj (McGee et al., 1985).

\section{Tefrocronologia por Traços de Fissão do Plio- Quaternário}

A datação por TF de esquilhas de vidro foi extensamente utilisada nos estudos tefrocronológicos da Nova Zelândia (entre outros, Shane et al., 1995; Naish et al., 1996; Seward \& Kohn, 1997; Shane, 2000) e na América do Norte (Boellstorff \& Te Punga, 1977; Boellstorff, 1978; Naeser et al., 1982; Westgate et al., 2001) e generalisadamente na crono-estratigrafia do Plio-Quaternário (e.g. Kyle \& Seward, 1984; Kasuya, 1990; Espizua \& Bigazzi, 1998; Westgate et al., 1998; Hermanns \& Schellenberger, 2008; Moriwaki et al., 2008). Datações de esquilhas de vidro e de zircões, quando presentes, se corroboram mutualmente (entre outros, Obradovitch et al., 1981; Seward \& Kohn, 1997).

Em outras circunstâncias, como na Colômbia Central, apenas os zircões resistiram às ações meteóricas de um clima tropical úmido e podem contribuir à cronologia numérica das formações superficiais vulcano-sedimentares que os encerram (Toro, 1999). Foi assim que na Colômbia Central, a datação por TF de mais de 130 zircões oriundos de três pontos de amostragem de uma stone line (Paton, 1995) do altiplano d'Antioquia (Hermelin, 1993), permitiu propor uma idade máxima de em
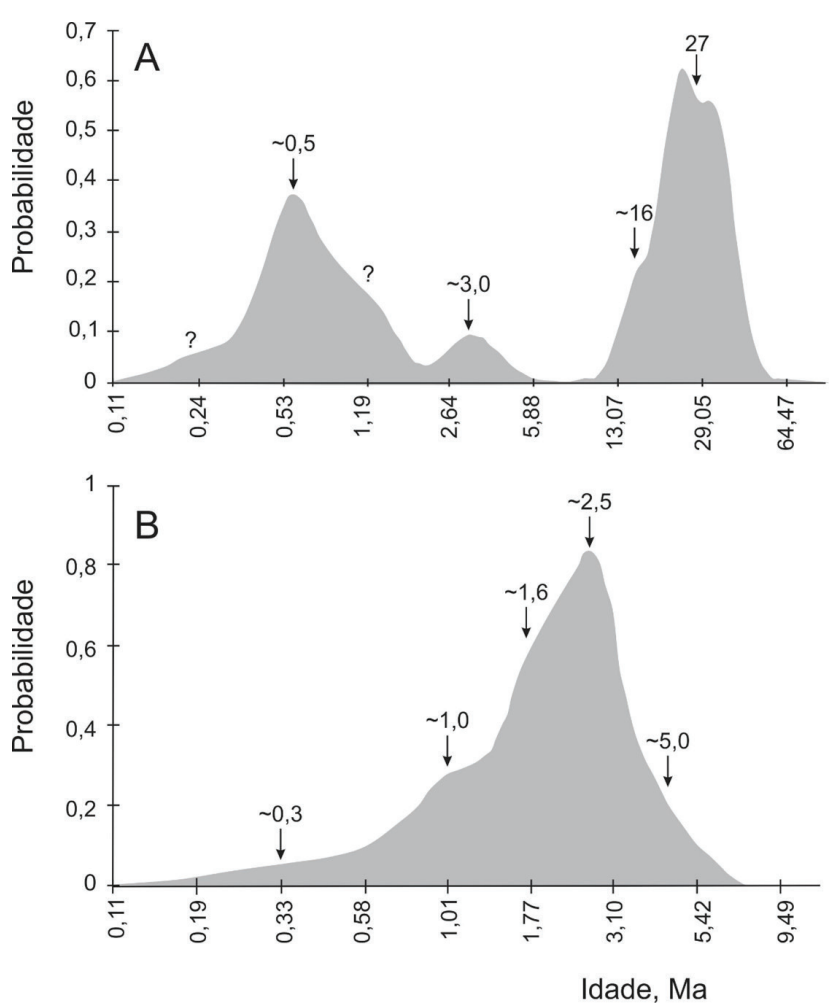

Figura 17. Diagramas de densidade de probabilidade (diagramas de Brandon, 1992, 1996) para as idades TF de zircões de dois níveis de tefras retrabalhadas, e Mount Tom, Massachusets, E.U.A. Em A, diagrama correspondendo aos 52 zircons da figura 16. Em B, diagrama composto onde estão reunidos os 133 zircões vulcânicos coletados em três sítios de uma stone line (segundo Toro, 1999).

Figure 17. Probability density diagrams (Brandon diagrams, 1992, 1996) for the FT ages of zircons of two levels of reworked tephra from Mount Tom, Massachusets, U.S. In $A$, diagram corresponding to the 52 zircons of figure 16 . In $B$, a composite diagram gathering the 133 volcanic zircons collected at three sites of a stone line (according to Toro, 1999). 
torno de $300 \mathrm{Ka}$ para a importante fase erosiva inicial (Toro, 1999; Toro et al., 2006) (Fig. 17). A análise da distribuição das idades TF dos zircões deste nível de referência, onde coexistem zircões vulcânicos automorfos e zircões do embasamento metamórfico de morfologia mais irregular, mostra a importância da datação de um número mais robusto de grãos nas tefras alteradas e/ou nas camadas que contêm elementos transportados e redepositados.

Datações de zircões de tefras, visando a calibração cronológica dos restos de hominídeos ou de suas indústrias, foram efetuadas no Rifte Valley do leste africano, na Tanzânia no Bed I das gargantas de Olduvai (Fleischer et al., 1965b), na Etiópia na formação de Hadar (Aronson et al., 1977; Walter, 1989), no Cindery Tuff do vale médio de Awash (Hall et al., 1984), no Kenia no tufo KBS (Gleadow, 1980) ou ainda no Membro Buluk (Hurford \& Watkins, 1987).

No norte do Paquistão, foram os TF que dataram a presença precoce do gênero Homo há em torno de dois milhões de anos (Johnson et al., 1982; Dennel et al., 1988). Na Indonésia, são os tufos de Java que enquadram o Homo erectus VIII de Sangiran (Nishimura et al., 1980) que foram datados por esta técnica; na Ilha de Flores, foi a datação TF em zircões de dois níveis de tufos vulcânicos da série estratigráfica de Mata Menge que permitiu situar a chegada do

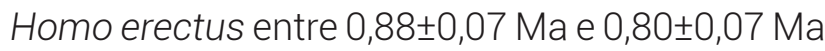
(Morwood et al., 1998).

\section{Outras aplicações dos traços de fissão em arqueologia}

Outras possibilidades foram utilizadas para datar fósseis humanos ou uma antiga indústria lítica. Este foi o caso na China, na caverna de Choukoutien, na qual restos do homem de Pequim, situados entre as unidades estratigráficas 3 e 13 das 17 que comportam o sítio, foram datados com esfênos 'queimados' encontrados, por centenas, junto às cinzas provindas da atividade humana. Medidas dos comprimentos dos traços de uma centena desses minerais, com granulometria compreendida entre 50 e 300 micra, mostraram que eles haviam perdido todos os traços fósseis pré-existentes aos aquecimentos, e as idades TF possibilitaram datar o sítio. As idades de $306 \pm 56$ Ka e $462 \pm 45$ Ka foram obtidas para os níveis estratigráficos 4 e 11 respectivamente, e enquadrariam assim os restos do Homo erectus pekinensis (Guo et al., 1980), citados em (Wagner \& Van den Haute, 1992; Guo et al., 1991) (Fig. 18).

No sul da China, a presença de vidros de impacto meteorítico (tectitos) teria permitido datar o depósito de artefatos líticos de Baigu, próximo de Baise, em Guanxi. Com efeito, tectitos e abundantes elementos dessa indústria coexistem em uma mesma camada situada a em torno de um metro de profundidade abaixo da superfície de um antigo terraço 'lateritizado', hoje situado no topo de uma colina do vale do rio Youjiang. A idade de 0,732 $\pm 0,039 \mathrm{Ma}$ de um dos tectitos (Guo et al., 1997) é concordante com a idade também determinada por TF de 0,693 $\pm 0,025 \mathrm{Ma}$ de outros tectitos do sudoeste da Asia (Storzer \& Wagner, 1980). $\mathrm{Na}$ medida em que nenhum outro indício de transporte ou remanejo teria afetado este material (Huang et al., 1990), esta idade foi considerada por Guo e colaboradores op.cit. como aquela do depósito. Estabelecendo-se, ao menos, um limite superior.

A datação direta por TF de fósseis de vertebrados seria em princípio possivel, graças à hidroxiapatita que constitui a trama mineral de suas partes ósseas e particularmente mais de $98 \%$ de seu esmalte dentário. Com efeito, a apatita é sem dúvida o mineral mais utilizado em geocronologia por TF, e a hidroxiapatita desses tecidos que praticamente não contém urânio nos seres vivos, podem conter de alguns ppm a algumas centenas de ppm post-mortem. Todavia, obstáculos aparentemente redibitórios que se referem tanto à visualização e observação dos traços fósseis quanto a processos diagenéticos (recristalizações, sequências de fixação e perda de urânio), parecem condenar esta via (Jolivet et al., 2008).

Outros potenciais domínios de aplicação, explorados nos anos 1960-1970, como a datação de cerâmicas e tijolos cozidos, por meio da presença de zircões ou ainda de vidros arqueológicos, foram limitados, devido às densidades muito baixas de traços fósseis e, para 


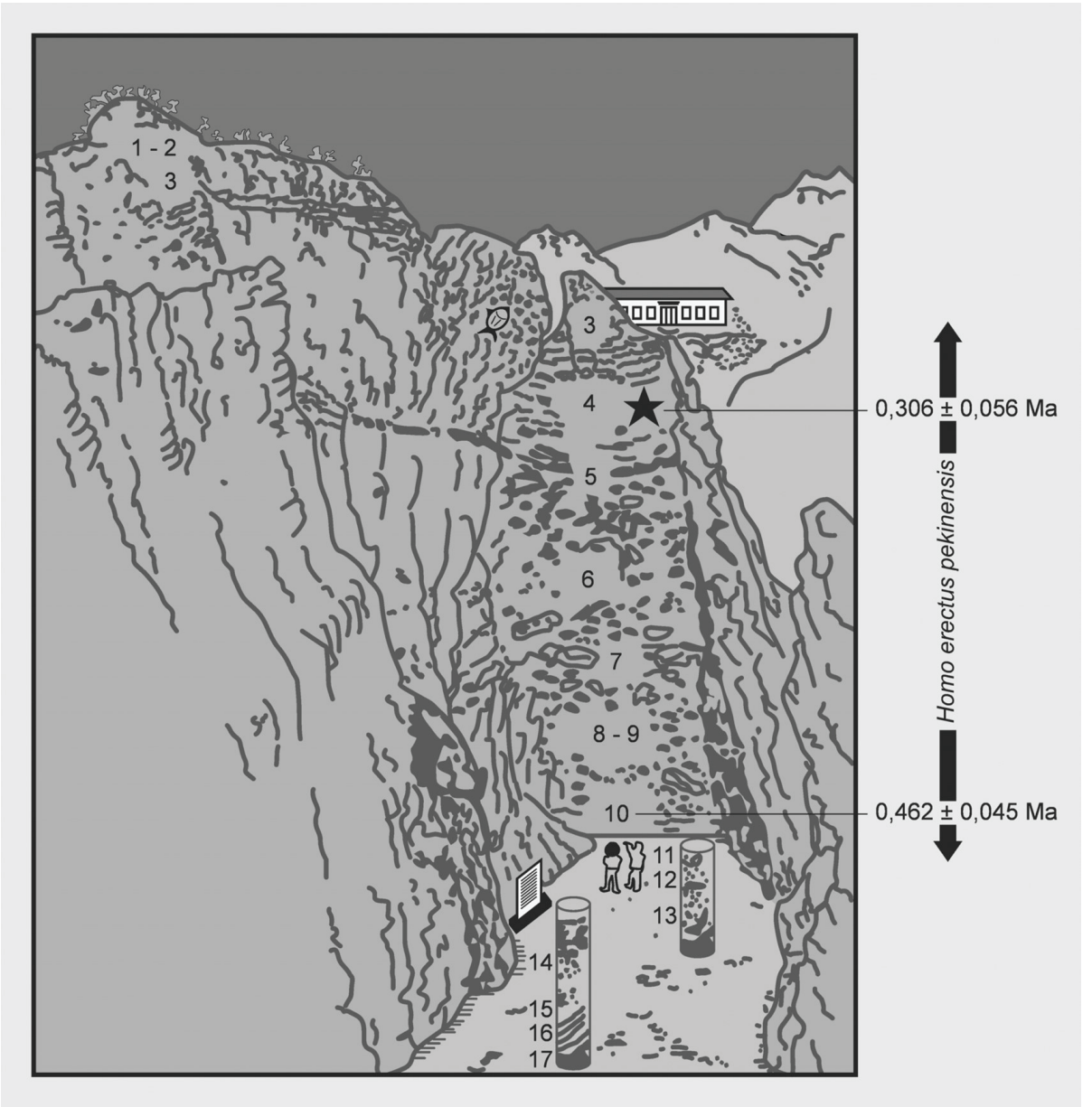

Figura 18. Perfil esquemático da série estratigráfica de Choukoutien indicando os níveis datados por TF (segundo Guo Shi Lun, 1991, modificado por G. Bigazzi, comunicação pessoal).

Figure 18. Schematic profile of Choukoutien stratigraphic serie indicating levels dated by FT (according to Guo Shi Lun (1991), modified by G. Bigazzi, personal communication).

os materiais compósitos recozidos, pela escassez desses minerais. Uma exceção refere-se aos vidros cujas cores amarelo-verde são devidas a adição de sais de urânio. Assim, o método dos traços pode ser utilizado para detetar falsos vidros de fabricação recente (Wagner, 1978). Ao contrário, a disposição de tais 'vidros da Boêmia' dopados com urânio e com idades de fabricação conhecidas, permitiu por meio da utilização das equações de idade 7' e 8', determinar com uma boa aproximação da constante de fissão espontânea $\lambda_{\mathrm{f}}$. Assim, um valor de 8,7 \pm 0,6 $\times 10^{-17}$ anos $^{-1}$ foi obtido (Wagner et al., 1975), concordante com o valor atual e considerado como o mais preciso de $8,46 \pm 0,06 \times 10^{-17}$ anos $^{-1}$ (Galliker et al., 1970).

Além disso, o método dos traços permite conhecer muito precisamente a distribuição de urânio nos tecidos ósseos a partir da irradiação em reator nuclear de uma seção delgada polida sobre a qual foi fixado um detetor externo. A revelação dos traços de fissão induzida permite obter uma cartografia da localização do urânio na escala da dezena de micra. Os teores de urânio se deduzem por meio da comparação entre as densidades de traços neste detetor e em um segundo detetor justaposto em uma amostrapadrão com teor de urânio conhecido, em uma mesma irradiação (Bahain et al., 1992; Hoffmann et al., 2008; Jolivet et al., 2008, Figs. 5 e 7) (Fig. 19). Esta técnica pode ser utilizada na datação de dentes fósseis de mamíferos por ressonância de spin eletrônico RPE para a determinação das doses de irradiação utilizadas (Yokoyama et al., 1981). O método dos traços pode então mostrar-se de primeira importância para a avaliação dosimétrica das doses de irradiação recebidas nas datações por resonância de spin eletrônico de dentes ou ossadas fósseis. Essas cartografias são somente relativas ao estado atual dos ambientes que frequentemente se comportam como sistemas abertos depois da primeira fixação pos-mortem de urânio nos tecidos dentários. 
A

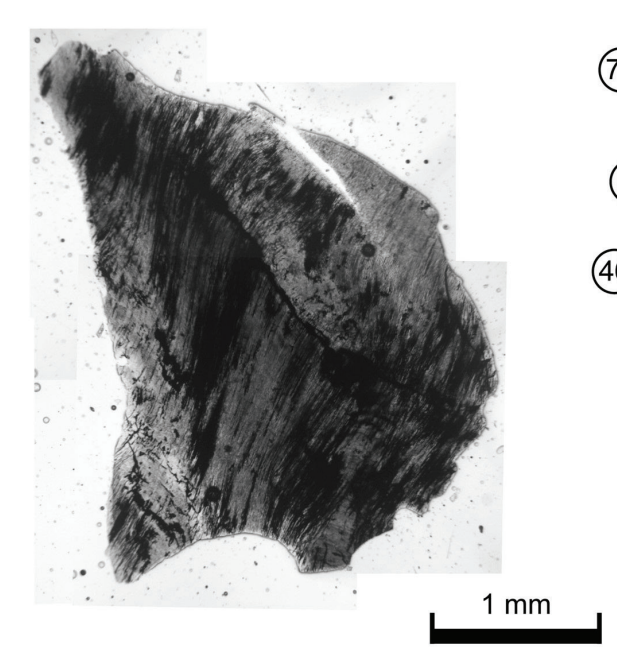

B

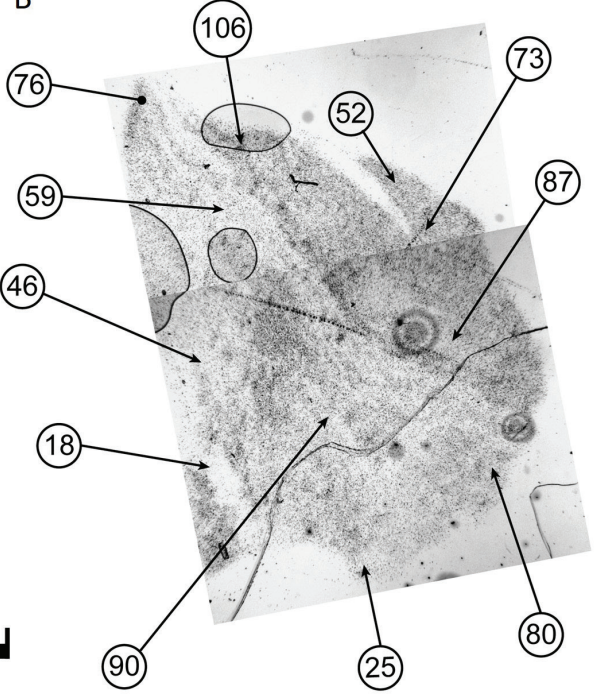

Figura 19. Distribuição do urânio em um fragmento de dente fóssil de elefante. A imagem à esquerda (A) ilustra a seção polida desse fragmento e à direita (B) a distribuição correspondente de urânio, registrada em um detetor externo. À direita (B), as zonas com contrastes mais ou menos intensos correspondem a densidades de traços mais ou menos elevadas (o aumento utilizado na imagem não permite distinguir os traços individuais). Os números indicam os teores locais em urânio em ppm, correspondentes. Cada número corresponde ao teor determinado em uma superfície de $100 \times 100$ microns. Aqui ele varia entre 18 e 106 ppm, mas as medidass efetuadas em outros fragmentos do mesmo dente mostram um espectro com teores compreendidos entre 15 e $214 \mathrm{ppm}$. A incerteza sobre os teores sempre é inferior a 10\% (modificado de Jolivet et al., 2008).

Figure 19. Distribution of uranium in an elephant fossil tooth fragment. The picture on the left (A) illustrates the polished section of this fragment and on the right $(B)$ the corresponding distribution of uranium, recorded on an external detector. On the right $(B)$, zones with more or less intense contrasts correspond to more or less high tracks densities (the magnification used in the picture does not allow to distinguish individual tracks). The numbers indicate the local correspondant levels in uranium, in ppm. Each number corresponds to the content determined on a surface of $100 \times 100$ microns. Here it varies between 18 and $106 \mathrm{ppm}$, but the measurements made in other fragments of the same tooth show a spectrum with contents between 15 and $214 \mathrm{ppm}$. Uncertainty about the levels is always less than 10\% (according to Jolivet et al., 2007, modified).

\section{Conclusões}

Referente à geocronologia do PlioQuaternario, o domínio de aplicação por TF limita-se praticamente aos vidros de impacto meteoríticos, às rochas vulcânicas e, particularmente às tefras que fornecem excelentes níveis de referência nas séries vulcano-sedimentares continentais, onde este método de datação numérica, com frequência é o único a poder intervir.

Em arqueologia, a principal utilização da datação por TF referiu-se ao estudo da circulação pré-histórica da obsidiana. Ela surge como complementar aos outros métodos de caracterização para encontrar as fontes desta matéria prima (Poupeau et al., 2007, 2008). A utilização do método dos traços para a datação propriamente dita de sítios repousa ora sobre a oportunidade ofertada pelos níveis de tefras mais ou menos remanejadas, ora sobre a ocorrência de minerais 'recozidos' ou até mesmo impactitos. Ele pode então suplantar a falta de outros meios de datação. Enfim, se dentes e ossos não podem ser datados por TF, esta técnica oferece a possibilidade de apresentar cartografias detalhadas da distribuição de urânio que poderiam permitir um refinamento das avaliações dosimétricas quando da datação por ressonância de spin eletrônico ou por luminescência estimulada. 
Um dos aspectos da datação TF que não foi abordado aqui porque ultrapassa o contexto deste manuscrito é aquele das idades TF inferiores a $5 \mathrm{Ma}$ encontradas nos minerais e em vidros pseudo-tachilitos dos embasamentos cristalinos ou da componente detrítica das formações sedimentares, e que refere-se à termocronologia isotópica.

Agradecimentos. Os autores agradecem Giulio Bigazzi (Istituto di Geoscienze e Georisorse, Pisa, Itália), Marc Jolivet (Université Montpellier II, Montpellier, França) e Gloria Toro (Université EAFIT, Medellin, Colômbia) pelo empréstimo das figuras de traços de fissão e pelas releituras atentas deste manuscrito.

In memoriam. Este artigo é dedicado à memória de Gérard Poupeau, incansável pesquisador, dedicado professor e estimado amigo. Nos anos 80, quando trabalhou no Centro Brasileiro de Pesquisas Físicas (CBPF), Gérard Poupeau nos permitiu conhecer o fascinante mundo dos traços de fissão e foi um dos divulgadores do método no Brasil.

\section{Referências}

Arias-Radi, G., Bigazzi, G. \& Bonadonna, F.P. 1972. Le tracce di fissione. Un metodo per lo studio della vie di commercio dell'ossidiana. Origini, 6: 155-170.

Arias, C., Bigazzi, G., Bonadonna, F.P., Cipolloni, M., Hadler, N.J.C., Lattes, C.M.G. \& Radi, G. 1984. Fission track dating in Archaeology. A useful application. In: Parrini Ed., Montedison Progetto Cultura, Scientific Metthodologies Applied to Works of Arts, p. 151-159.

Arias, A., Oddone, M., Bigazzi, G., Di Muro, A., Principe, C. \& Norelli, P. 2006. New data for the characterization of Milos obsidians. Journal of Radioanalytical and Nuclear Chemistry, 268: 371-386.

Aronson, J.L., Schmitt, T.J., Walter, R.C., Taieb, M., Tiercelin, J.J., Johanson, D.C., Naeser, C.W. \& Nairn, A.E.M. 1977. New geochronologic and palaeomagnetic data for the hominid-bearing Hadar formation of Ethiopia. Nature, 267: 323-
327.

Bahain, J.J., Yokoyama, Y., Falguères, C. \& Sarcia, M.N. 1992. ESR dating of tooth enamel: a comparison with $\mathrm{K}-\mathrm{Ar}$ dating. Quaternary Science Reviews, 11: 245-250.

Balestrieri, M.L., Bigazzi, G., Bouska, V.J., Labrin, E., Hadler, J.C.N., Kitada, N., Osorio A., A.M., Poupeau, G., Wadatsumi, K. \& Zúñiga, G.A. 1998. Potential glass age standards for fissiontrack dating: an overview. In: P. Van den Haute \& F. de Corte Eds., Advances in Fission-Track Geochronology. Kluwer Academic Publishers, Dordrecht, p.287-304.

Bandhari, N., Bhat, S.G., Lal, D., Rajagopalan, G., Tamhane, A.S. \& Venkatavaradan, V.S. 1971 Fission fragment tracks in apatite: recordable track lengths. Earth and Planetary Science Letters, 13:191-199.

Bellot-Gurlet, L. 1998. Caractérisation par analyse élémentaire PIXE \& ICP-MS-AES d'un verre naturel: I'obsidienne. Application à l'étude de provenance d'objets archéologiques. Grenoble, 290p. Thèse de Doctorat, Université Grenoble 2.

Bellot-Gurlet, L., Bigazzi, G., Dorighel, O., Oddone, M., Poupeau, G. \& Yegingil, Z. 1999. The fissiontrack analysis: An alternative technique for provenance studies of prehistoric obsidian artefacts. Radiation Measurements, 3: 639644.

Bigazzi, G. \& Bonadonna, F.P. 1973. Fission track dating of the obsidian of Lipari island Italy. Nature, 242: 322-323.

Bigazzi, G. \& Galbraith, R.F. 1999. Point-counting technique for fission-track dating of tephra glass shards, and its relative standard error. Quaternary Research, 51:67-73.

Bigazzi, G. \& Radi, G. 1981. Datazione con le tracce di fissione per l'identificazione della provenienza dei manufatti di ossidiana. Rivista di Scienze Preistoriche, XXXVI (1/2): 223-250. Bigazzi, G. \& Radi, G. 1998. Prehistoric exploitation of obsidian for tool making in the Italian peninsula: a picture from a rich fission-track data-set. In: II INTERNATIONAL CONGRESS OF PREHISTORIC AND PROTOHISTORIC SCIENCES, Forlì, Italy, p.149-156.

Bigazzi, G., Marton, P., Norelli, P. \& Rozloznik, L. 1990. Fission track dating of Carpathian 
obsidians and provenance identification, Nuclear Tracks and Radiation Measurements, 17: 391-396.

Bigazzi, G., Hadler, J.C.N., I unes, P.J.\&Osorio A.A.M. 1991. Fission tracks DS/DI measurements in artificial glass under conditions free from fading and radiation. Nuclear Instruments and Methods in Physics Research B, 53: 67-70.

Bigazzi, G., Coltelli, M., Hadler, N.J.C., Osorio Araya, A.M., Oddone, M. \& Salazar, E. 1992. Obsidianbearing lava flows and pre-Colombian artifacts from the Ecuadorian Andes: first new multidisciplinary data. Journal of South American Earth Sciences, 6: 21-32.

Bigazzi, G., Ercan, T., Oddone, M., Ozdogan, M. \& Yeğingil, Z. 1993. Application of fission track dating to archaeometry: provenance studies of prehistoric obsidian artifacts. Nuclear Tracks and Radiation Measurements, 22: 757-762.

Bigazzi, G., Yeğingil, Z., Ercan, T., Oddone, M. \& Ozdogan, M. 1994. Provenance studies of prehistoric artifacts in Eastern Anatolia: interdisciplinary research results. Mineralogica and Petrographical Acta, XXXVII: 17-36.

Bigazzi, G., Poupeau, G., Yeğingil, Z. \& BellotGurlet, L. 1998. Provenance studies of obsidian artefacts in Anatolia using the fission-track dating method: an overview. In: M.C. Cauvin, A. Gourgaud, B. Gratuze, N. Arnaud, G. Poupeau, J.L. Poidevin \& C. Chataigner Eds L'Obsidienne au Proche \& Moyen Orient, Du volcan à l'outil', Archaepress, Oxford, p.69-89.

Bigazzi, G., Bonadonna, F.P., Centamore, E., Leone, G., Mozzi, M., Nisio, S. \& Zanchetta, G. 2000. New radiometric dating of volcanic ash layers in Periadriatic foredeep basin system. Paleogeography Paleoclimatology Paleoecology, 155: 327-340.

Bigazzi, G., Hadler Neto, J.C., lunes, P.J. \& OsorioAraya, A.M. 2005a. Fission-track dating of South-American natural glasses: an overview. Radiation Measurements, 39: 585-594.

Bigazzi, G., Laurenzi, M.A. \& Viramonte, J.G. 2005b. The obsidian from Quiron Salta Province, Argentina: a new reference glass for fission-track dating. Radiation Measurements, 39: 613-616.

Bigazzi, G., Laurenzi, M.A., Soligo, M. \& Tuccimei, P. 2008. Multi-method approach to dating glass: the case of Baziluzzo Islet Aeolian archipelago, Italy. Journal of Volcanology and Geothermal Research, 177: 244-250.

Boellstorff, J. 1978. North American Pleistocene stages reconsidered in light of probable Pliocene-Pleistocene continental glaciations. Science, 202: 305-307.

Boellstorff, J. \& Te Punga, M.T. 1977. Fissiontrack ages and correlation of middle and lower Pleistocene sequences from Nebraska and New Zealand. New Zealand Journal of Geology and Geophysics, 20: 45-58.

Bonetti, R., Guglielmetti, A., Malerba, F., Migliorini, E., Oddone, M. \& Bird, R. 1998. Age determination of obsidian source samples from North Queensland and New South Wales, Australia. In: P. Van den Haute \& F. de Corte (Ed.). Advances in Fission-Track Geochronology, Kluwer Academic Publishers, Dordrecht, p.305-312.

Brandon, M.T. 1992. Decompositon of fissiontrack grain-ages distribution. American Journal of Science, 292: 535-564.

Brandon, M.T. 1996. Probability density plot for fission-track grain-age samples. Radiation Measurements, 26: 663-676.

Braun, J., Van der Beek, P. \& Batt, G. 2006. Quantitative Thermochronology. United Kingdom Cambridge University Press, 258p.

Cauvin, M.C., Gourgaud, A., Gratuze, B., Arnaud, N., Poupeau, G., Poidevin, J.L. \&

Chadderton, L.T. 2003. Nuclear tracks in solids: registration physics and the compound spike. Radiation Measurements, 36: 13-34.

Chataigner, C. 1998. L'obsidienne au Proche et Moyen Orient: du volcan á I'outil. BAR International series 738, Archaeopress, Oxford, 388p.

Chataigner, C., Badalian, R., Bigazzi, G., Cauvin, M.C., Jrbashian, R., Karapetian, S.G., Norelli, P., Oddone, M. \& Poidevin, J.L. 2003. Provenance studies of obsidian artefacts from Armenian archaeological sites using the fission-track dating method. Journal of Non-Crystalline Solids, 323: 167-171.

Dennel, R.W., Rendell H. \& Hailwood E. 1988. Early tool making in Asia: two-million-year old artefacs in Pakistan. Antiquity, 62: 98-106.

Dickin, A.P. 1995. Radiogenic Isotope Geology, 
Cambrige University Press, 490p.

Dorighel, O. 2000. La diffusion de l'obsidienne préhispanique dans l'aire andine équatoriale de 3.500 à 1.500 AD. Proposition d'une première modélisation des échanges par traces de fission et géochimie. Paris, 449p. Thèse de Doctorat, Université Paris I.

Dorighel, O., Poupeau, G., Bellot-Gurlet, L. \& Labrin, E. 1998. Fission track dating and provenance of archaeological obsidian artefacts in Colombia and Ecuador. In: P. Van den Haute \& F. de Corte (Ed.). Advances in Fission-Track Geochronology, Kluwer Academic Publishers, Dordrecht, p.313-324.

Durrani, S.A., Khan, H.A., Taj, M. \& Renfrew, C. 1971. Obsidian source identification by fission track analysis. Nature, 223: 242-245.

Espizua, L.E. \& Bigazzi, G. 1998. Fission-track dating of the Punta de Vacas glaciation in the Rio Mendoza valley, Argentina. Quaternary Science Reviews, 17: 755-760.

Fleischer, R.L. \& Hart, H.R. 1972. Fission Track Dating: Techniques and Problems. In: W.W. Bishop, D.A. Miller \& S. Cole Eds., Calibration of Hominoid Evolution, Scottish Academic Press, Edinburgh, p.135-170.

Fleischer, R.L., Price, P. B., Symes, E.M. \& Miller, D.S. 1964. Fission Track Ages and TrackAnnealing Behavior of Some Micas. Science, 43: 349-351.

Fleischer, R.L., Price, P.B. \& Walker, R.M. 1965a. The ion explosion spike mechanism for formation of charged particle tracks in solids. Journal of Applied Physics, 36: 3645-3652.

Fleischer, R.L., Price, P.B., Walker, R.M. \& Leakey, L.S.B. 1965b. Fission Track Dating of Bed I, Olduvai Gorge. Science, 148: 72-74.

Fleischer, R.L., Price, P.B., Walker, R.M. \& Leakey, L.S.B. 1965c. Fission track dating of a mesolithic knife. Nature, 205: 1138.

Fleischer, R.L., Price, P.B. \& Walker, R.M. 1975. Nuclear Tracks in Solids. University of California Press, Berkeley, 604p.

Galbraith, R.F. 1981. On statiscal models for fission track counts. Mathematical Geology, 13: 471-478.

Galbraith, R.F. 1990. The radial plot: graphical assessment of spread in ages. International Nuclear Tracks and Radiation Measurements,
17: 207-214.

Galbraith, R.F. \& Green, P.F. 1990. Estimating the component ages in a finite mixture. Nuclear Tracks and Radiation Measurements, 17: 197206.

Galbraith, R.F. \& Laslett, G.M. 1993. Statistical models for mixed fission track ages. Nuclear Tracks and Radiation Measurements, 21: 459470.

Galliker, D., Hugentobler, E. \& Hahn, B. 1970. Spontane Kernspaltung von $238 \mathrm{U}$ und 241 Am. Helvetica Physica Acta 43: 593-606.

Gleadow, A.J.W. 1980. Fission track age of the KBS tuff and associated hominid remains in northern Kenya. Nature, 284: 225-230.

Green, P.F. 1981. A new look at statistics in fission track dating. Nuclear Tracks, 5: 77-86.

Guedes, S., Hadler N, J.C., Iunes, P.J., Paulo, S.R. \& Zuñiga, A. 2000. Spontaneous fission decay Constant of $238 \mathrm{U}$ using SSNTD. Journal of Radioanalytical and Nuclear Chemistry, 245(2): 441-442.

Guo, S.L. 1997. Fission track dating of ancient man site in Baise, China, and its significance in space research, paleomagnetism and stratigraphy. Radiation Measurements, 28: 565-570.

Guo, S.L., Zhou, S., Meng, W., Zhang, P., Hao, X., Liu, S., Zhang, F., Hu, R. \& Liu, J. 1980. Fission Track dating of Peking man. Kexue Tongba, 25: 770-772.

Guo, S.L., Liu, S., Sun, S., Zhang, F., Zhou, S., Hao, X., Hu, R., Meng, W., Zhang, P. \& Liu, J. 1991. Age and duration of Peking man site by fission track method. Nuclear Tracks and Radiation Measurements, 19: 719-724.

Hadler N., J.C., Lattes, C.M.G., Marques, A., Marques, M.D.D., Serra, D.A.B. \& Bigazzi, J. 1981 Measurements of the spontaneousfission disintegration Constant of ${ }^{238} \mathrm{U}$. Nuclear Tracks, 5 (2): p. 45-52. 08502.00/0

Hall, C. M., Walter, R.C., Westgate, J.A. \& York, D. 1984. Geochronology, statigraphy and geochimistry of Cindery Tuff in Pliocene hominid-bearing sediment of the middle Awash, Ethiopia. Nature, 308: 26-31.

Hermanns, R.L. \& Schellenberger, A. 2008. Quaternary tephrochronology helps define conditioning factors and triggering 
mechanisms of rock avalanches in NW Argentina. Quaternary International, 178(1): 261-175.

Hermelin, M. 1993. Stone line in Antioquia. Quaternary of South America and Antarctic Peninsula, 8: 198-216.

Hoffmann, D.L., Paterson, B.A. \& Jonckheere, R. 2008. Measurement of the uranium concentration and distribution in a fossil equid tooth using fission tracks, TIMS, and laserablation ICP-MS: implications for ESR dating. Radiation Measurements, 43(1): 5-13.

Huang, W., Leng, J., Yuan, X. \& Xie, G. 1990. Advanced opinion on the stratigraphy and chronology of Baise stone industry. Acta Anthropologica Sinica, 9: 105-111.

Hurford, A. J., Fitch, F.J. \& Clarke 1984. Resolution of the age structure of the detritical zircon populations of two Lower Cretaceous sandstones from the Weald of England by fission track dating. Geology Magasine, 121: 269-396.

Hurford, A.J. \& Watkins, R.T. 1987. Fission-track age of the tuffs of the Buluk Members, Bakate formation, Northern Kenya: a suitable fissiontrack age standard. Chemical Geology, 66: 209-216.

Johnson, G.D., Zeidler, P., Naeser, C.W., Johnson, N.M., Summer, S.D., Frost, C.D., Opdyke, N.D. \& Tahhrikheli, R.A.K. 1982. The occurrence and fission-track ages of late Neogene and Quaternary volcanic sediments, Siwalik Group, northern Pakistan. Paleogeography, Paleoclimatology, Paleoecology, 37: 63-93.

Jolivet, M., Lebatard, A.E., Reyss, J.L., Bourlès, D., Mackaye, H.T., Lihoreau, F., Vigneau, P. \& Brunet, M. 2008. Can fossil bones and teeth be dated using fission track analysis?. Chemical Geology, 247(1/2): 81-99.

Kasuya, M. 1990. Fission-track ages of tuff layers related to the Pliocene-Pleistocene boundary on the Boso peninsula, Japan. Quaternary Research, 33: 86-93.

Khlopin, W.G. \& Gerlin, E.K. 1947. Une nouvelle method pour la détermination des âges absolus de minéraux en russe. Doklady Akademii Nauk SSSR, 58:1415-1417.

Koshimizu, S. 1981. Source areas of obsidian found in the prehistoric sites in the Ishikari-
Tomakomai low-land area in Hokkaido, Japan. Earth Science, 35: 267-273.

Krishnaswami, S., Lal, D., Prabhu, N. \& MacDougall, D. 1974. Characteristics of fission tracks in zircon: applications to geochronology and cosmology. Earth and Planetary Science Letters, 22: 51-59.

Kyle, P.R. \& Seward, D. 1984. Dispersed rhyolitic tephras from New Zealand in deep-sea sediments of the Southern Ocean. Geology, 12: 487-490.

Le Bourdonnec, F.X., Lugliè, C., Dubernet, S., Bohn, M. \& Poupeau, G. 2005. Monte Arci Sardinia obsidians: new geochimical data from electron microprobe and ion beam analysis. In: L'OSSIDIANA DEL MONTE ARCI NEL MEDITERRANEO - LE VIE DELL'OSSIDIANA NEL MEDITERRANEO ED IN EUROPA, ATTI DEL $3^{\circ}$ CONVEGNO INTERNAZIONALE, Pau, France, p.129-140.

Le Bourdonnec, F.X., Poupeau, G. \& Lugliè, C. 2006. SEM-EDS analysis of western Mediterranean obsidians: a new tool for Neolithic provenance studies. Comptes Rendus en Geosciences, 338: 1150-1157.

Lugliè, C., Le Bourdonnec, F.X., Poupeau, G., Atzeni, E., Dubernet, S., Moretto, P. \& Serani, L. 2007. Early Neolithic obsidians in Sardinia Western Mediterranean: the Su Carroppu case. Journal of Archaeological Science, 34: 428-439.

McGee, V.E., Johnson, N.M. at Naeser C.W. 1985. Simulated fissioning of uranium and testing of the fission-track dating method. Nuclear Tracks and Radiation Measurements, 10: 365379.

Marcolini, F., Bigazzi, G., Bonadonna, F.P., Centamore, E., Cioni, R. \& Zancheta, G. 2003. Tephrochronology and tephrostratigraphy of two Pleistocene continental fossiliferous successions from Central Italy. Journal of Quaternary Science, 18: 545-556.

Marcos, J. G., Alvarez Perez, A. \& Bigazzi, G. 1998. El tráfico a distancia temprano entre la hoya de Quito y la península de Santa Elena: las evidencias de Real Alto. In: F. CárdenasArroyo \& T. Bray (Ed.). Intercambio y Comercio Entre Costa, Andes y Selva: arqueología y etnohistoria de Suramérica, Universidad de Los Andes, Bogotá, p.163-184. 
Maurette, P., Pellas, P. \& Walker, R.M. 1964. Etude des traces de fission fossiles dans le mica. Bulletin de la Société Française de Minéralogie et de Cristallographie, 87: 6-17.

McDowell, F.W., McIntosh, W.C. \& Farley, A. 2005. A precise ${ }^{40} \mathrm{Ar} /{ }^{39} \mathrm{Ar}$ age for the Durango apatite $\mathrm{U}-\mathrm{Th} / \mathrm{He}$ and fission-track dating standard. Chemical Geology, 214: 249-263.

Meshick, A.P., Verkhovsky, A.B., Assonov, S.S. \& Shukolyukov, Y. A. 1987. A new method of dating young uranium minerals. Doklady Akademii Nauk SSSR, 293: 1476-1478.

Miller, D.S. \& Wagner, G.A. 1981. Fission-track ages applied to obsidian artifacts from South America using the plateau-annealing and the track-size age-correction techniques. Nuclear Track, 5: 147-155.

Moriwaki, H., Westgate, J., Sandhu, A.S., Preece, S.J. \& Arai, F. 2008. New glass fission-travck ages of middle Pleistocene tephras on Yakushima Island, southern Japan. Quaternary International, 178(1):128-137.

Morwood, M.J., O'Sullivan, P.B., Aziz, E. \& Raza, A. 1998. Fission track ages of stone tools and fossils in central Flores, Indonesia. Nature, 392: 173-176.

Naeser, C.W., Izett, G.A. \& Obradovitch, J.D. 1980 Fission-track and $\mathrm{K}$-Ar ages of natural glasses. U. S. Geological Survey Bulletin, 1489: 1-31.

Naeser, N.D., Westgate, J.A., Hughes, O.L. \& Péwé, T.L. 1982. Fission-track ages of late Cenozoic distal tephra beds in the Yukon Territory and Alaska. Canadian Journal of Earth Sciences, 19: 2167-2178.

Naish, T., Kamp, P.J.J., Alloway, B.V., Pillans, B., Wilson, G.S. \& Westgate, J. 1996. Integrated tephrochronology and magnetostratigraphy for cyclothemic marine strata, Wanganui basin: implications for the Pliocene-Pleistocene boundary in New Zealand. Quaternary International, (34/36): 29-48.

Nishimura, S. 1980. Re-examination of the fission-track ages of volcanic ashes and ignimbrites in Sumatra. In: S. Nishimura (Ed.). Physical geology of Indonesian island arcs, Kyoto University, p.148-153.

Nishimura, S., Thio, K.H. \& Hehuwat, F. 1980. Fission-track ages of the tuffs of the Pucangan and Kabuh formations, and the tektite at
Sangiran, central Java. In: S. Nishimura (Ed.). Physical geology of Indonesian island arcs, Kyoto University, p.72-80.

Obradovitch, J.D., Naeser, C.W., Izett, G.A., Pasini, G. \& Bigazzi, G. 1981. Ages constraints on the proposed Plio-Pleistocene boundary stratotype at Vrica, Italy. Nature, 298: 55-59.

Paton, T.R. 1995. Soils, a New Global View, Yale Univesity Press, New Heaven, 234p.

Poupeau, G. 1982. Precision, meaning and accuracy of fission tracks dating. In: Indian Academy of Science Ed., Nuclear Tracks, Bangalore, p.67-100.

Poupeau, G., Labrin, E., Sabil, N., Bigazzi, G., Arroyo, G. \& Vatin-Pérignon, N. 1993. Fission track dating of 15 Macusanite glass pebbles from the Macusani volcanic field, SE Peru. Nuclear Tracks and Radiation Measurements, 21: 499-506.

Poupeau, G., Dorighel, O., Bellot-Gurlet, L. \& Toro, G. 1995. La datacion por huellas de vidrios naturales y artificiales. Aplicaciones en arqueologia. Revista Ingeominas, 5: 37-58.

Poupeau, G., Bigazzi, G., Bellot-Gurlet, L. \& Dorighel, O. 1998. Fission-track dating of obsidians and archaeology. In: M. C. Cauvin, A. Gourgaud, B. Gratuze, N. Arnaud, G. Poupeau, J.-L. Poidevin \& C. Chataigner Eds., L'Obsidienne au Proche et Moyen Orient, Du volcan à l'outil, Archaeopress, Oxford, p.53-68. Poupeau, G., Dorighel, O. \& Toro, G. 2002. Datation par traces de fission et préhistoire. In: J.C. Miskovsky (Ed.). Géologie de la préhistoire Association pour l'étude de l'environnement géologique de la préhistoire, Paris, p.12591272.

Poupeau, G., Le Bourdonnec, F.X., Dubernet, S., Scorzelli, R.B., Duttine, M. \& Carter, T. 2007. Tendances actuelles dans la caractérisation des obsidiennes pour les études de provenance, ArcheoSciences. Revue d'Archéométrie, 31: 79-86.

Poupeau, G., Le Bourdonnec, F.X., Dubernet, S. \& Delerue, S. 2008. Instrumental methods of obsidian characterization and prehistoric obsidian provenance studies: the current status. In: F. Sternke, L. J. Costa \& L. Eigeland (Ed.). PROCEEDINGS OF THE XVth CONGRESS OF THE INTERNATIONAL UNION 
OF THE PREHISTORIC AND PROTOHISTORIC SCIENCES, NON-FLINT RAW MATERIAL USE IN PREHISTORY: OLD PREJUDICES AND NEW DIRECTIONS, Archaeopress, Oxford.

Price, P.B. \& Walker, R.M. 1963. Fossil tracks of charged particles in mica and the age of minerals. Journal Geophysics Research, 68: 4847-4862.

Sandhu, A. S., Westgate, J.A. \& Alloway, B.V. 1993. Optimizing the isothermal plateau fissiontrack dating method for volcanic glass shards. Nuclear Tracks and Radiation Measurements, 21: 479-488.

Seward, D. \& Kohn, B.P. 1997. New fissiontrack ages from New Zealand Quaternary tephra: an interlaboratory experiment and recommendations for the determination of young ages. Chemical Geology, 141: 127-140.

Shackley, M.S. 1998. Archaeological obsidian studies: method and theory. Advances in Archaeological and Museum Science, Plenum Press, London, 243p.

Shane, P., Froggatt, P., Black, T. \& Westgate, J. 1995. Chronology of Pliocene and Quaternary bioevents and climatic events from fissiontrack ages on tephra beds, Wairarapa, New Zealand. Earth and Planetary Science Letters, 130: 141-154.

Shane, P. 2000. Tephrochronology: a New Zealand case study. Earth Science Reviews, 49: 223259.

Shukolyukov, Y.A., Ashkinadze, G.S. \& Komarov, A.N. 1974. A new Xe-Xe neutron-activated method of mineral dating. Doklady Akademii Nauk SSSR, 219: 952-954.

Soares, C.J. Guedes, S., Curvo, E.A.C. Hadler, J.C., Jonckheere, R., Tello S.C.A., LixandrãoFilho, A., Siqueira, P.T.D. \& Madifilho, T. 2014. Recalibration of U-doped standard glasses through uranium thin film for neutron-fluence measurements. Journal of Radioanalytical and Nuclear Chemistry, 2: 17-26,

Storzer, D. \& Wagner, G.A. 1969. Correction of thermally lowered fission track ages of tektites. Earth and Planetary Science Letters, 5: 463-468.

Storzer, D. \& Poupeau, G. 1973. Ages-plateaux de minéraux et verres par la méthode des traces de fission. Comptes Rendus de l'Académie des Sciences, Paris, D276: 137-139.

Storzer, D. \& Wagner, G.A. 1980. Australites older than indochinites. Naturwissenshaften, 67: 90-91.

Suzuki, M. 1969. Fission track identification of geologic source of obsidian artifacts collected from the Stone Site. Archaeological Journal, 36: 12-15.

Suzuki, M. 1973. Chronology of prehistoric human activity in Kanto, Japan. Journal of the Faculty of Science, 5 (3-4): 241-469.

Szeines, G. 1996. Thermal spike model of amorphous track formation in insulators irradiated by swift heavy íons. Nuclear Instruments and Methods in Physics Research B, 116: 141-144.

Toro, E.G. 1999. Téphrochronologie de la Colombie centrale département d'Antioquia, abanico de Pereira. Une approche stratigraphique, géochimique, minéralogique et géochronologique par $14 \mathrm{C}$ et traces de fission. Grenoble, 299p. Thèse de Doctorat, Université Joseph Fourier, Grenoble I.

Toro, E.G., Hermelin, M., Schwabe, E., Posada, O. B., Silva, D. \& Poupeau, G. 2006. Fission-track dating and geomorphic evidences for longterm stability in the central cordillera highlands, Colombia. Zeitschrift fur Geomorphology, 45: 1-16.

Toulemonde, M., Paumier, E., \& Dufour, C. 1993. Thermal Spike model in the electronic stopping power regime. Radiation Effects and Defects in Solids, 126: 201-206.

Van den Haute, P., Jonckheere, R. \& de Corte, F. 1988. Thermal a neutron fluence determination for fission-track dating with metal activation monitors: a re-investigation. Chemical Geology, 73: 233-244.

Virk, H.S., Singh, G. \& Bigazzi, G. 1989. Fission track dating of Lipari obsidians. Indian Journal of Pure and Applied Physics, 27:187-188.

Von Gunten, H.R. 1969. Distribution of mass in spontaneous and neutron-induced fission. Actinides Review, 1: 275-298.

Wagner, G.A. 1978. Archaeological applications of fission track dating. Nuclear Track Detection, 2: 51-63.

Wagner, G. \& Van den Haute, P. 1992. FissionTrack Dating, Kluwer Academic Publishers, 
Dordrecht, 285p.

Wagner, G.A., Carpenter B.S., Faul, H., Van der Linden, R., Gijbels, R. \& Reimer, G.M. 1975. The spontaneous fission rate of $\mathrm{U}-238$ and fission track dating. Geochimica and Cosmochimica Acta, 39: 1279-1286.

Walter, R.C. 1989. Application and limitation of fission-track geochronology to Quaternary tephras. Quaternary International, 1: 35-46.

Watanabe, N. \& Suzuki, M. 1969. Fission track dating of archaeological glass materials from Japan. Nature, 222: 1057-1058.

Westgate, J.A. 1989. Isothermal plateau fissiontrack ages of hydrated glass shards from silicic tephra beds, Earth and Planetary Science Letters, 95: 226-234.

Westgate, J.A., Shane, P.A.R., Pearce, N.J.G., Perkins, W.T., Korosettar, R., Chesner, C.A., Williams, M.A.J. \& Acharyya, S.K. 1998. All Toba tephra occurrences across peninsular India belong to the 75,000 BP eruption. Quaternary Research, 50: 107-112.

Westgate, J., Preece, S.J., Froese, D. G., Walter, R.C., Sandhu, A.S. \& Schweger, C.E. 2001. Dating early and middle Reid Pleistocene glaciations in central Yukon, Canada. Quaternary Research, 56(3): 288-306.

Whetstone, S.L. 1963. Coincident Time-of-Flight Measurement of the Velocities of ${ }^{252} \mathrm{Cf}$ Fission Fragments. Physical Review, 131: 1232-1243.

Yeğingil, Z. \& Göksu, Y. 1982. Fission-Track dating of obsidians. Nuclear Tracks, 6: 43-48.

Yokoyama, Y., Quagebeur, J.P., Bibron, R., Léger, C., Nguyen, H.V. \& Poupeau, G. 1981. Electron Spin Resonance ESR dating of bones of the Caune de I'Arago at Tautavel. In: DATATIONS ABSOLUES ET ANALYSES ISOTOPIQUES EN PRÉHISTOIRE- MÉTHODES ET LIMITES - COLLOQUE INTERNATIONAL DU CNRS, Tautavel, France, p. 457-492. 